\title{
Employees' Death Awareness and Organizational Citizenship Behavior: A Moderated Mediation Model
}

\author{
Alexandra Jacobsen ${ }^{1}$ (D) $\cdot$ Terry A. Beehr ${ }^{2}$ (D) \\ Accepted: 11 September 2021 / Published online: 3 December 2021 \\ (c) The Author(s), under exclusive licence to Springer Science+Business Media, LLC, part of Springer Nature 2021
}

\begin{abstract}
The purpose of this study is to develop and test a theoretical model that distinguishes how death anxiety and death reflection influence organizational citizenship behavior (OCB) directed towards the organization (OCB-O) and individuals within it (OCB-I). We draw from terror management and posttraumatic growth (PTG) theories to argue for prosocial motivation as a mediator for these relationships. We also examine organizational identification (OI) as a potential moderator. Data were collected from 241 employees every month for 3 months. Our findings support the mediating role of prosocial motivation. Death anxiety was negatively related to prosocial motivation, whereas death reflection was positively related to prosocial motivation. In turn, prosocial motivation was positively related to OCB-I and OCB-O. Regarding moderation, lower levels of OI strengthened the indirect effects of death anxiety on OCB-I and OCB-O through prosocial motivation. However, OI did not moderate the indirect effects of death reflection on OCB-I or OCB-O. These results highlight the conceptual differences between death anxiety and death reflection. In addition, these results emphasize the need to explore death anxiety and death reflection in organizational research.
\end{abstract}

Keywords Death anxiety $\cdot$ Death awareness $\cdot$ Death reflection $\cdot$ Organizational citizenship behavior $\cdot$ Prosocial motivation

Death is a universal event that can deeply affect people in many ways (Greenberg et al., 2004; Yalom, 2008). This includes employees, whose innate thoughts and emotions surrounding death can profoundly affect their attitude, motivation, and behavior in the workplace (Grant \& WadeBenzoni, 2009). In spite of the potential importance of death awareness for employee responses, researchers have devoted little attention to its role in the workplace, even though there have been several calls to do so (e.g., Grant \& Wade-Benzoni, 2009; Sliter et al., 2014; Stein \& Cropanzano, 2011). It is for this reason that there is a strong need for researchers to investigate the influence of death awareness in the workplace.

Death awareness refers to the extent to which people are conscious of their own mortality (i.e., mortality salience; Grant \& Wade-Benzoni, 2009). People can process death

Alexandra Jacobsen

jacob2a@cmich.edu

1 Department of Management, Central Michigan University, Mount Pleasant, MI, USA

2 Department of Psychology, Central Michigan University, Mount Pleasant, MI, USA and mortality through their thoughts and negative emotions, also referred to as their death reflection and death anxiety, respectively (see Grant \& Wade-Benzoni, 2009 for a review). Considering the negative connotations often associated with death, it is surprising that both death anxiety and death reflection have been consistently related to promoting and engaging in helping behavior (e.g., Cozzolino et al., 2004; Jacobsen \& Beehr, 2018; Jonas et al., 2002; McAdams $\&$ de St. Aubin, 1992). These findings seem to suggest that both death anxiety and death reflection can drive positive and even selfless behavior.

Although these findings have greatly contributed to our understanding of the outcomes associated with death anxiety and death reflection, there remain several issues that need to be addressed in order to advance death awareness research. First, explicit empirical support for the construct validity of death anxiety and death reflection is lacking. Despite researchers conceptualizing death anxiety and death reflection differently, similar positive findings related to helping behavior make it unclear the extent to which these constructs are valuable and worth investigating independently. It is even more concerning that there is no existing evidence that we are aware of that simultaneously examines both processes 
in the same study. Therefore, our primary goal with this research is to establish some much-needed construct validity evidence of death anxiety and death reflection by being one of the first to simultaneously examine the effects of these constructs on helping behavior.

In doing so, we also address previous calls to examine death awareness in the workplace by examining the effects of employee's death anxiety and death reflection on workrelated helping behavior. Researchers have long argued that death awareness, death anxiety, and death reflection can be related to organizational life (Grant \& Wade-Benzoni, 2009; Stein \& Cropanzano, 2011), but there is relatively little empirical research on the topic. This is important given that many of the outcomes associated with death anxiety and death reflection in a social context (e.g., sharing resources with others) heavily overlap with factors that are paramount to the functioning and success of organizations (Ehrhart \& Naumann, 2004; Podsakoff et al., 2000). One such factor is organizational citizenship behavior (OCB), which are employees' discretionary behaviors that are not formally trained, demanded, or rewarded as part of the job (MacKenzie et al., 1993; Organ, 1997; Van Scotter et al., 2000; Williams \& Anderson, 1991). Thus, our study investigates employee's helping behavior by specifically examining OCB.

Second, the underlying reasons for death anxiety and death reflection being associated with helping behavior have not been empirically explored. Although death anxiety and death reflection are positively related to helping behavior, extant theory implies that there may be selfish and altruistic reasons for why people experiencing these thoughts and emotions help others (Greenberg et al., 1986; Tedeschi \& Calhoun, 2004). This suggests that people's motives for helping others after experiencing death anxiety or death reflection may not be as straightforward as originally thought. Therefore, to help clarify whether employees' actions are driven by selfless, other-oriented reasons, we examine prosocial motivation as an underlying mechanism through which death anxiety and death reflection influence OCB.

Third, it is not clear how the organization influences the extent to which employees with death anxiety or death reflection become motivated to help others. Despite the death literature emphasizing identification as an important factor that influences the behavior of people with death anxiety or death reflection (Greenberg et al., 1986; Janoff-Bulman, 1992; Tedeschi \& Calhoun, 2004), little is known about the extent that employees identifying with the organization can impact this relationship. This is surprising given that employees who identify with their organization adopt the structural foundation provided by the organization and embody key attitudes and behavior represented by the organization (Hogg et al., 1995). This suggests that the organization may contribute to how employees with death anxiety or death reflection help others. Therefore, we also investigate organizational identification (OI) as a potential moderator of the indirect relationships of death anxiety and death reflection on OCB (see Fig. 1).

\section{Theoretical Background and Hypothesis Development}

\section{Death Awareness as a Multidimensional Construct}

Research in terror management and posttraumatic growth (PTG) have found that people who become aware of their mortality act in a variety of ways, from being hostile towards others and focusing on materialistic gain to being supportive and driven to pursue intrinsic goals (Cozzolino et al., 2004; Greenberg et al., 1986; McGregor et al., 1998). These findings across two distinct streams of research have led researchers to propose a more unified approach to death awareness using Metcalfe and Mischel's (1999) hot/coolsystem (Grant \& Wade-Benzoni, 2009). That is, death awareness is a dual system of motivation and action that has both an affective and cognitive component, referred to as death anxiety and death reflection.

Death anxiety refers to "an unpleasant emotion of multidimensional concerns that is of an existential origin provoked on contemplation of death of self or others" (Nyatanga \& de Vocht, 2006, p. 413). People who are anxious about death tend to exhibit extreme and vivid negative emotions (e.g., fear, dread, panic) when faced with mortality (Cozzolino et al., 2004). These individuals are more likely to engage in behavior that is quick, impulsive, and self-protective in nature (Grant \& Wade-Benzoni, 2009). As a result, people

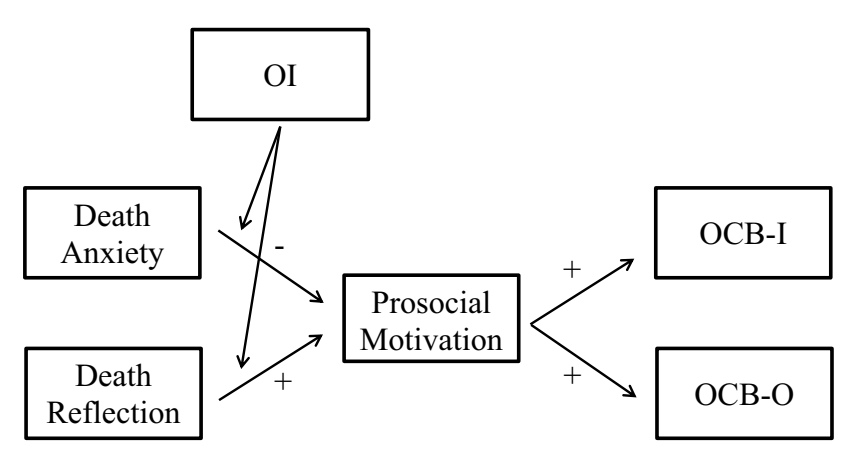

Fig. 1 Proposed moderated mediation model. OI=organizational identification. OCB- $\mathrm{I}=$ organizational citizenship behavior directed at individuals. $\mathrm{OCB}-\mathrm{O}=$ organizational citizenship behavior directed at the organization 
with death anxiety tend to experience adverse effects on their psychological well-being (Juhl \& Routledge, 2016; Sliter et al., 2014).

Death reflection, on the other hand, refers to the extent to which individuals review their life, contemplate their meaning and purpose, and take perspective of how others will view them after their death (Cozzolino et al., 2004). People who reflect on death tend to have intrinsic thoughts and behavior (Kasser, 2002). These individuals are more aware of their own existence and feel responsibility to change one's life (Yalom, 2008). Compared to death anxiety, death reflection is a more cognitive state where individuals' thoughts on death are processed deliberately, analytically, and rationally (Grant \& Wade-Benzoni, 2009).

\section{Death Anxiety and Death Reflection as Predictors of OCB}

Employees' OCB are discretionary helping behaviors that can be directed at the organization (OCB-O) or at individuals within it (OCB-I). Research on death anxiety and death reflection suggests that people who are aware of their mortality are more likely to respond in ways that help others (Cozzolino et al., 2004; Jonas et al., 2002). We propose, however, that death anxiety and death reflection may serve as predictors of OCB, but in different ways. In the following sections, we draw from the terror management and PTG literature to discuss how death anxiety and death reflection are related to OCB.

\section{Death Anxiety and OCB from a Terror Management Perspective}

According to terror management theory (TMT; Greenberg et al., 1986), people are anxious about death because they have a strong desire to live despite knowing that death is unavoidable. This raises the question of how humans function when cognizant of their inevitable demise. Greenberg and colleagues (Greenberg et al., 1986) proposed that people try to pursue and maintain two cultural anxiety buffers to defend against anxiety. The first buffer, a cultural worldview, refers to a set of standards that establishes order, permanence, and stability. People can maintain their worldview and reduce their death anxiety by actively following and promoting the standards set by that worldview. The second cultural anxiety buffer, self-esteem, refers to one's perception that they are a valuable member of a meaningful universe. People can protect against death anxiety through their self-esteem by displaying attributes that are highly valued by their worldviews. Overall, TMT suggests that employees with death anxiety can defend against the existential threat of death by reaffirming their own values as well as the values of the group with whom they identify.
From a TMT perspective, employees can protect against their death anxiety by displaying behavior that boosts their worldviews or self-esteem (Greenberg et al., 1986; Lambert et al., 2014). These behaviors can range from destructive behavior, such as punitively evaluating people who oppose their worldviews (McGregor et al., 1998), to seemingly constructive behavior, such as donating their personal resources to causes that promote their worldviews (Jonas et al., 2002). On the surface, this suggests that employees are more likely to engage in OCB-I and OCB-O; however, we argue otherwise. First, by definition OCB are not a part of an employee's job description, and employees are not formally trained or informed that they need to perform these behaviors (Organ, 1988). As such, employees with death anxiety are not going to perform OCB very often because these individuals need direct guidance on the ways in which they can uphold and maintain the values set by their worldview. Second, OCBs are not guaranteed to be rewarded by the organization (Organ et al., 2006), which conflicts with the expectations of employees with death anxiety. These individuals expect that they will receive a reward from the organization or its stakeholders in return for upholding their worldviews (i.e., relief from their death anxiety). Third, employees experiencing death anxiety are selective about who they help (Greenberg et al., 1986). These individuals require that the organization or stakeholders share the same worldviews as they do to receive their assistance. As a result, these employees are naturally going to perform fewer OCB than people with less restrictive criteria because they have fewer people they are willing to help. Given this logic, we hypothesize that employees who are more anxious about death will engage in fewer OCB-I and OCB-O.

Hypothesis 1: Death anxiety is negatively related to (a) OCB-I and (b) OCB-O.

\section{Death Reflection and OCB from a PTG Perspective}

TMT research has primarily focused on the negative emotional reactions people have when faced with death; however, people are also cognitive beings. They can also think about and cognitively process death. According to PTG theory, this reflection on life and death can spur a positive psychological change in individuals (Tedeschi \& Calhoun, 2004). For this change to occur, however, individuals need to be willing to challenge and restructure their assumptive world when thinking about death. An assumptive world refers to a general set of beliefs and assumptions about the world that guides behavior, helps interpret information and events, and provides purpose and meaning (Janoff-Bulman, 1992; Tedeschi \& Calhoun, 2004). When people challenge their own assumptive world, they cognitively reframe their beliefs and assumptions based on their prior experiences. As 
a result, these individuals experience psychological growth such as having a greater appreciation for life, developing closer relationships with others, and striving to achieve intrinsic goals (Kasser, 2002; Tedeschi \& Calhoun, 1996).

Using PTG theory, we argue that employees who reflect on death are more likely to engage in OCB-I and OCB-O. This is because people who reflect on death have a strong desire to connect with others through their actions and identities (Ring \& Elsaesser Valarino, 1998). For example, these individuals are more likely to seek out opportunities to support and promote the well-being of other organizational members through teaching, mentoring, and informal leadership (McAdams \& de St. Aubin, 1992). A study by Cozzolino and colleagues (Cozzolino et al., 2004) found that participants were more likely to help others by sharing their raffle tickets with others after reflecting on their death. These individuals also have a strong desire to pursue goals that benefit larger institutions, such as organizations. After the events of $9 / 11$, several employees were motivated to do work that could facilitate the growth of their community and society (Wrzesniewski, 2002). Based on this rationale and evidence, we propose the following:

Hypothesis 2: Death reflection is positively related to (a) OCB-I and (b) OCB-O.

\section{Prosocial Motivation as a Mediator}

Prior research has focused on the direct relationships of death anxiety and death reflection on helping behavior. However, there is reason to believe that these relationships may be indirect. According to TMT, the reason why people who are anxious about death help others is because their actions may give them relief from their death-related anxiety (Greenberg et al., 1986; Lambert et al., 2014). In addition, PTG theory suggests that the reason why people who reflect on death help others is because it satisfies their internal desire to assist society (Tedeschi \& Calhoun, 1996; Wrzesniewski, 2002). Based on these theories, it seems that people who are aware of death need to have some rationale or motive for engaging in helping behavior that is encouraged by death awareness. Several researchers have also noted that death anxiety and death reflection have distinct and profound effects on motivation (Grant \& Wade-Benzoni, 2009; Pyszczynski et al., 2003). What is not entirely clear, however, is the type of motivation that links these relationships.

At a glance, it appears that people who are aware of death seek to help others in order to gain from it or to selflessly assist others (Grant \& Wade-Benzoni, 2009). The problem is that research on death anxiety and death reflection have developed independently, and the theories surrounding these constructs are inherently focused on either selfserving or other-serving purposes. As a result, there is no way of truly knowing if the reason why people with death anxiety or death reflection help others is entirely selfless or not. One way we can clarify this issue is by examining a motive where people greatly value and feel accountable for other's well-being. In the OCB literature, people with prosocial motives have a strong desire and sense of responsibility to improve the lives of others (Grant, 2007, 2008). As a result, these individuals are more likely to act in ways that can make meaningful contributions to others (Grant \& Mayer, 2009; Meglino \& Korsgaard, 2004). We believe that this overt focus on others may be the key to distinguishing the reasons why people with death anxiety and death reflection help others. Thus, we propose that prosocial motivation may serve as a potential mediating mechanism that can help distinguish the underlying motives of death anxiety from death reflection.

Prosocial motivation is defined as the desire to expend effort to provide, support, assist, and promote the well-being of others (Batson, 1987; Grant, 2007). Employees who are prosocially motivated prefer work that can be meaningful to others so they can better assist and be more valuable to others (Grant, 2008). Prosocially motivated employees are more likely to invest time and energy into their work because they are cognizant of the impact their behavior can have on others and value the outcomes that can result from their behavior (Vroom, 1964). Unsurprisingly then, evidence has found prosocial motivation to be a strong predictor of OCB (Rioux \& Penner, 2001). This is because employees with prosocial tendencies are more likely to focus on others' well-being and recognize when others need help (Grant \& Mayer, 2009). These individuals also tend to feel more accountable for others' well-being and prioritize others' interests ahead of their own (Grant, 2007, 2008; Meglino \& Korsgaard, 2004). This strong association between prosocial motivation and OCB, paired with the core theme underlying the TMT and PTG literature that self- versus other-oriented mechanisms link death anxiety and death reflection to employee behavior (Grant \& Wade-Benzoni, 2009), gives us reason to believe that prosocial motivation, an other-oriented motive, would serve as an ideal mechanism to explain the conceptual differences between death anxiety and death reflection and how these influence helping behavior at work.

According to TMT, people with death anxiety help others in order to establish a sense of security and self-preservation (Greenberg et al., 1986; Lambert et al., 2014). For instance, these individuals are more likely to donate money when they perceive the charity to identify with their worldview (Jonas et al., 2002). When their awareness of mortality is heightened, these individuals are also more willing to make selfsacrifices for their country in exchange for symbolic immortality (Routledge \& Arndt, 2008). These findings suggest that displays of generosity exhibited by people who are anxious about death serves as a defense mechanism to protect 
themselves. This makes sense because people with death anxiety are often overwhelmed from the intense negative emotions they are experiencing. They do not have enough emotional energy or resources to prioritize the needs of others without gaining some form of personal benefit (Byron $\&$ Peterson, 2002). This selfish gain goes against the fundamental principles of prosocial motivation, which suggest that people engage in behavior for the sake of helping others or pursuing the goals of the larger group. Therefore, we argue that employees who are anxious about death will be less prosocially motivated and in turn less likely to engage in either form of OCB.

According to PTG theory, the reason why people who reflect on death help others is because of a psychological growth that changes their underlying attitudes and motivations towards life (Tedeschi \& Calhoun, 1996, 2004). For example, these individuals can become less greedy, have enhanced gratitude, and develop a sense of transcendence after reflecting on their death (Cozzolino, 2006; Cozzolino et al., 2004; Frias et al., 2011). They also have a strong desire to help and connect with others, which drives these people to build long lasting relationships with individuals, groups, and even organizations (Peterson \& Stewart, 1996; Ring \& Elsaesser Valarino, 1998). In their pursuit of fulfilling this desire, these individuals begin to prioritize work with social value, such as mentoring others or helping the community (Erikson \& Erikson, 1998; Wrzesniewski, 2002). These individuals also start to promote the safety initiatives of the organization (Jacobsen \& Beehr, 2018). This evidence suggests that people who reflect on death become driven and make it a priority to help others. Thus, we argue that employees who reflect on death are more prosocially motivated and subsequently more likely to engage in both types of OCB.

To summarize, we propose that prosocial motivation mediates the relationships of death anxiety and death reflection on OCB-I and OCB-O. More specifically, we propose partial mediation rather than full mediation. Phenomena explored in social and organizational research tends to have several possible explanations (Baron \& Kenny, 1986). Given that death anxiety and death reflection are guided by two separately developed research streams, it is extremely likely that there are alternative explanations to explain why people with death anxiety or death reflection help others (Holland et al., 2016; MacKinnon et al., 2012). Thus, we hypothesize the following:

Hypothesis 3: Prosocial motivation partially mediates the (a) negative relationship between death anxiety and OCB-I and the (b) negative relationship between death anxiety and OCB-O.
Hypothesis 4: Prosocial motivation partially mediates the (a) positive relationship between death reflection and OCB-I and the (b) positive relationship between death reflection and OCB-O.

\section{OI as a Moderator of the Indirect Relationship}

Up to this point, we have argued for the differentiation of the indirect effects of death anxiety and death reflection on OCB using TMT and PTG theory. A closer examination of these theories, however, suggests that there is one commonality between them: TMT's cultural worldviews and PTG theory's assumptive world. Both theories propose that people cultivate and depend on a set of beliefs and assumptions to guide their actions, provide explanations for what happens, and offer a sense of meaning and self-worth (e.g., Greenberg et al., 1986; Janoff-Bulman, 1992; Tedeschi \& Calhoun, 2004). This theoretical overlap suggests that an employee's assumptions and beliefs are integral components to understanding how death anxiety and death reflection influence OCB through prosocial motivation.

We argue that employees rely on the beliefs and assumptions presented by the organization to guide their behavior. Although employees can seek defined beliefs and assumptions from several social domains, employees are more likely to refer to the guidelines offered by organizations when they are in a workplace setting. This is because organizations can provide a structural outline of the attitudes and behaviors that promote success in the workplace (van Knippenberg $\&$ van Schie, 2000). One way in which we can determine if employees embody the organization's values, goals, and norms is by examining their OI (Haslam, 2004).

OI refers to employees' sense of oneness with or belonging to their organization (Ashforth \& Mael, 1989). Employees who strongly identify with their organization describe themselves in accordance with their organizational membership and become invested in their organization's successes and failures (Mael \& Ashforth, 1992). In doing so, members can satisfy their need for self-worth and understanding of who they are (Abrams \& Hogg, 1988). This suggests that OI can have a strong influence on employee's motivation and behavior, making OI a possible boundary condition of the partial indirect relationship between death anxiety and death reflection on OCB through prosocial motivation. Specifically, we propose that OI serves as a first-stage moderator of the partially mediated relationships. That is, the moderation in the moderated mediation occurs at the first step of the model, meaning that OI moderates the relationships of death anxiety and death reflection on prosocial motivation.

The influence of death anxiety and death reflection on employees' motivation and subsequent behavior greatly depends on their own assumptions and beliefs (Cozzolino et al., 2004; Greenberg et al., 1986). From a TMT 
perspective, employees with death anxiety are motivated to assist others and organizations because they can receive relief from their anxiety in exchange for their actions. This only occurs, however, when the person being helped identifies with and shares the same worldviews as the other employee (Wu et al., 2016), which is more likely if that person is also an employee of the same organization and the helper has high OI. In addition, employees who are anxious about their death and strongly identify with their organization are more likely to defend the organization from potential harm (e.g., poor reputation; Greenberg et al., 1992; McGregor et al., 1998; Routledge \& Arndt, 2008). Therefore, we expect that the negative indirect relationship of death anxiety and both types of OCB will be weaker (or even positive) when OI is higher and exacerbated when $\mathrm{OI}$ is lower.

In contrast to death anxiety, employees reflecting on their death are going to have different motivations for how they interact with others depending on their level of OI. When these employees do not identify with the organization (low OI), they perceive that the organization does not have their employees' best interests in mind. As a result, lower-OI employees reflecting on death are even more motivated to take it upon themselves to care for and improve the lives of those around them (Yalom, 2008). PTG proposes that these individuals are going to be motivated to selflessly help others in these types of situations, as helping others can give employees who reflect on their death a desired sense of meaning and purpose in their life (Ring \& Elsaesser Valarino, 1998; Tedeschi \& Calhoun, 2004). In addition, these employees are motivated to get along with and unite others (Peterson \& Stewart, 1996). If they see a disconnect between employees and the organization, then they are going to be even more motivated to take action and help both parties by engaging in behaviors that promote the organization's goals. We therefore expect OI to serve as a first-stage moderator of the positive indirect relationship between death reflection and both types of OCB. Specifically, we propose this relationship to be stronger when $\mathrm{OI}$ is lower.

Hypothesis 5a: OI moderates the partially indirect negative relationship of death anxiety with OCB-I through prosocial motivation, such that the relationship is stronger when $\mathrm{OI}$ is lower.

Hypothesis 5b: OI moderates the partially indirect negative relationship of death anxiety with OCB-O through prosocial motivation, such that the relationship is stronger when $\mathrm{OI}$ is lower.

Hypothesis 6a: OI moderates the partially indirect positive relationship of death reflection with OCB-I through prosocial motivation, such that the relationship is stronger when OI is lower.
Hypothesis 6b: OI moderates the partially indirect positive relationship of death reflection with OCB-O through prosocial motivation, such that the relationship is stronger when OI is lower.

\section{Method}

\section{Participants and Procedures}

We collected data from US employees across several industries. These employees were recruited using Amazon's Mechanical Turk (MTurk), an online service that recruits and pays respondents from a diverse workforce to complete virtual tasks, including surveys and questionnaires. Online panel data is a widely recognized data collection method that has been shown to be as valid and reliable as other forms of data collection in the organizational literature (Goodman et al., 2013; Walter et al., 2018). That is, the results for employee samples from such data panels are not different from organizationally sourced samples, which is the most important issue for researchers. In addition, research shows that MTurk workers are attentive to instructions (Keith et al., 2017) and are good, if not better, than other online services (e.g., Qualtrics) in regard to passing attention checks (Kees et al., 2017). MTurk workers have also been found to be a strong representation of the US population (Keith et al., 2017) with little to no differentiation in biases from other samples (Goodman et al., 2013). These studies have led several scholars to conclude that there is no sufficient evidence to suggest that MTurk data is less accurate than other methods of data collection (Keith et al., 2017).

We had employees complete a survey once a month at three time points to reduce common method effects (Podsakoff et al., 2012). The most appropriate time interval to use in measuring variables at different stages of the model is not known, but one month is in the range of time periods used in studies that find effects for some other negatively valenced variables in the organizational sciences (e.g., Liu et al., 2019; Naseer et al., 2020; Zhang et al., 2020).

To ensure the quality of our data, we implemented several recommended best practices for MTurk data at each stage of the study (Aguinis et al., 2020). We determined the qualifications participants needed in advance to determine if MTurk was an appropriate data collection method. We conducted a screener study and invited individuals to participate in our study if they had at least a 90 percent approval rating for successfully completing tasks, were over the age of 21 , and were employed for at least 6 months (Peer et al., 2014). When the study was implemented, we monitored the MTurk community websites to ensure our study was ethical, timely, and met expectations 
as indicated at the beginning of the study (e.g., compensation, exclusion criteria, awareness of attention checks). We addressed MTurker inattentiveness by including at least three attention checks and several reverse-worded items in each survey (Cheung et al., 2017; DeSimone et al., 2015). For data screening, participants were eliminated if they did not select the correct attention check response, gave the same responses to positively and negatively worded items in a scale, completed a survey too quickly (i.e., less than two minutes), or if they were identified as responding with insufficient effort (i.e., gave same answer for over $80 \%$ of the survey).

Overall, 543 US employees completed the survey at Time 1 , of which 82 were removed from the study due to selecting the incorrect attention check response $(n=63)$, completing the survey too quickly $(n=18)$, or being identified as loweffort responders $(n=1)$. A month later, 436 of the remaining 461 employees completed the Time 2 survey. A total of 72 employees were eliminated due to responding incorrectly to attention check responses $(n=50)$, completing the survey too quickly $(n=18)$, or responding with insufficient effort $(n=4)$. One month later, we invited 328 of the 364 employees to complete the survey at Time 3 . We deleted 56 responses because of failure to select the correct attention check response $(n=48)$, finishing the survey too quickly $(n=6)$, or putting minimal effort into the survey $(n=2)$. Together, a total of 272 employees completed the entire study. From this sample, 31 were removed during data cleaning because their codes could not be matched across time points $(n=6)$, large amounts of data were missing $(n=24)$, or they were identified as a multivariate outlier $(n=1)$.

The final sample consisted of 241 employees ( $44 \%$ retention rate from Time 1). Of these, $60 \%$ were female $(n=145)$, $43 \%$ were between 30 and 39 years of age $(n=104), 65 \%$ graduated from college $(n=157)$, and $79 \%$ were Caucasian $(n=190)$. In addition, $83 \%$ were full-time employees $(n=200)$, with an average work experience of 6.47 years $(S D=6.25)$.

We also tested for potential nonresponse bias, as some participants either did not return to participate in the study $(11 \%)$ or were removed from the study in the data cleaning process (44\%). To do this, we followed Rogelberg and Stanton's (2007) recommendation to conduct a wave analysis by comparing the study variables and demographics (e.g., sex and age) between participants who were removed from (or dropped) the study at different time points and the final sample. We did this by running an analysis of variance (ANOVA) to test the differences in means across groups. Results found that there were no significant differences between groups for any of the variables tested $(F<1.50)$. Although we cannot completely eliminate the possibility of nonresponse bias, these results do minimize concerns of nonresponse bias being present in the final sample.

\section{Measures}

Employees completed the negative affectivity (NA), death anxiety, death reflection, and OI scales at Time 1, the prosocial motivation scale at Time 2, and the OCB scale at Time 3.

Death anxiety was measured using nine items $(\alpha=.95)$ from Thorson and Powell's (1992) Revised Death Anxiety Scale (RDAS). We used a shortened version of this scale to reduce participant fatigue (Hinkin, 1995), as the survey distributed at Time 1 contained items from a separate data collection effort. We selected items by examining the corrected item-total correlation (CITC) values collected from two separate data collection efforts (see Appendix 19 for results). The first data collection effort was collected from 175 undergraduate students across 2 time points, of which death anxiety and death reflection were measured at Time 2. In the second data collection effort, data was collected from 163 employees across 4 time points, of which death anxiety and death reflection were measured at Time 1. All items retained had a CITC value greater than or equal to .60 . An example item was "The subject of life after death troubles me greatly." Response choices ranged from 1 (strongly disagree) to 7 (strongly agree).

Death reflection was measured using nine items $(\alpha=.90)$ from Jacobsen and Beehr's (2018) death reflection scale. Similar to the death anxiety measure, we used a shortened version of this scale to reduce participant fatigue (Hinkin, 1995). We selected items by examining the corrected itemtotal correlation (CITC) values collected from the same data collection efforts used for death anxiety and a third data collection effort, which was cross-sectional and consisted of 192 adults (see Appendix 20 for results). All items retained had a CITC value greater than or equal to .60. An example item includes "I think about how people will remember me (when I die)." Response choices ranged from 1 (never) to 7 (always).

$O I$ was measured using five items $(\alpha=.89)$ from Mael and Ashforth's (1992) OI scale, which was adapted to fit the current sample. For example, the item "The Army's successes are my successes" was adapted to "My organization's successes are my successes." Response choices ranged from 1 (strongly disagree) to 7 (strongly agree).

Prosocial motivation was measured using five items ( $\alpha=$.93) from Grant and Sumanth's (2009) prosocial motivation scale. An example item was "I like to work on tasks that have the potential to benefit others." Response choices ranged from 1 (strongly disagree) to 7 (strongly agree).

$O C B$ was measured using Lee and Allen's (2002) 16-item OCB scale. Of these, eight items $(\alpha=.87)$ measured OCB-I and eight items $(\alpha=.90)$ measured OCB-O. Example items were "Help others who have been absent" and "Express loyalty towards the organization" for OCB-I and OCB-O, 
respectively. Response choices ranged from 1 (never) to 7 (daily).

Following recommendations to select conceptually meaningful control variables (Becker et al., 2016; Breaugh, 2008; Carlson \& Wu, 2012), we chose age, sex, and NA as controls because of the theoretical ties these variables have to death and mortality salience. In the death anxiety literature, younger people report higher levels of death anxiety than older people (Neimeyer \& Moore, 1994). This also aligns with socioemotional selectivity theory (SST), which suggests that adults maximize their emotional and attitudinal experiences towards life when they age and become aware that their time is finite (Carstensen et al., 1999). In addition, research has found that women report higher levels of death anxiety than men (Belmi \& Pfeffer, 2016; Kastenbaum, 2000). Lastly, NA has been found to be strongly related to generalized anxiety, which has also been recognized as a predictor of death anxiety (Jolly et al., 1994; Pollak, 1980). We measured NA using the 10 -item $(\alpha=.91)$ Positive and Negative Affect Schedule (PANAS; Watson et al., 1988).

\section{Confirmatory Factor Analysis}

Confirmatory factor analyses (CFA) were conducted to examine the discriminant validity of the study variables using LISREL 8.80 (Jöreskog \& Sörbom, 1993). We used item parcels to reduce model complexity and account for the relatively smaller sample size when compared to the number of parameters (Bagozzi \& Edwards, 1998; Nasser \& Takahashi, 2003). We also chose to use item parcels because they can be more reliable and normally distributed than individual items (Little et al., 2002). Following Little and colleagues' (Little et al., 2002) suggestions, we created item parcels by matching items with the highest and lowest corrected item-total correlations (CITC).

First, we analyzed the discriminate validity of death anxiety and death reflection. A two-factor model for death awareness fit the data well $\left(\chi^{2}(19)=32.25, p=.03\right.$; RMSEA $=.05$; $\mathrm{SRMR}=.03 ; \mathrm{CFI}=.99 ; \mathrm{IFI}=.99)$ and improved model fit when compared to a one-factor model $\left(\Delta \chi^{2}(1)=668.78\right.$, $p<.001)$. We then assessed the discriminant validity of OCB-I and OCB-O. A two-factor model for OCB fit the data well $\left(\chi^{2}(19)=33.03, p=.02 ;\right.$ RMSEA $=.06 ; \mathrm{SRMR}=.02$; $\mathrm{CFI}=.99 ; \mathrm{IFI}=.99)$ and improved model fit when compared to a one-factor model $\left(\Delta \chi^{2}(1)=261.85, p<.001\right)$. We then assessed a six-factor model including all variables in the study's model, which is reported in Table 1. It adequately fit the data $\left(\chi^{2}(155)=237.73, p<.001\right.$; $\operatorname{RMSEA}=.05$; $\mathrm{SRMR}=.04 ; \mathrm{CFI}=.98 ; \mathrm{IFI}=.98)$ and improved model fit when compared to a five-factor model combining OCB-I and OCB-O $\left(\Delta \chi^{2}(5)=273.65, p<.001\right)$, a five-factor model combining death anxiety and death reflection $\left(\Delta \chi^{2}\right.$ $(5)=697.05, p<.001)$, a four-factor model combining the OCB factors and death awareness factors $\left(\Delta \chi^{2}(9)=967.95\right.$, $p<.001)$, and a one-factor model combining all study variables $\left(\Delta \chi^{2}(15)=2,551.11, p<.001\right)$. These analyses provided support for the discriminant validity of the study variables.

\section{Results}

Table 2 reports the descriptive statistics, reliabilities, and intercorrelations among the study variables. The reliabilities of all variables were good, ranging from .87 to .95 . It is also important to note that we ran analyses without control variables (e.g., age, sex, and NA) and found no substantive changes to the final results.

\section{Hypothesis Testing}

We used LISREL to test the hypotheses (see Fig. 2). Hypotheses 1 and 2 proposed that death anxiety and death reflection were related to OCB-I and OCB-O. As reported in Table 4, death anxiety was negatively related to OCB-I $(\beta=-.17$, $p<.01)$ and OCB-O $(\beta=-.16, p<.01)$ after controlling age, sex, NA, and OI. Death reflection was positively related to OCB-I $(\beta=.24, p<.01)$ and OCB-O $(\beta=.17, p<.01)$ after controlling age, sex, NA, and OI. This provides support for Hypotheses 1a through $2 \mathrm{~b}$.

Table 1 Confirmatory factor analyses (CFA) comparing hypothesized model to alternative models

\begin{tabular}{|c|c|c|c|c|c|c|c|c|}
\hline Model & $\chi^{2}$ & $d f$ & RMSEA & SRMR & CFI & IFI & $\Delta \chi^{2}$ & $\Delta d f$ \\
\hline Model 1: Hypothesized six-factor model & $237.73^{* *}$ & 155 & .05 & .04 & .98 & .98 & & \\
\hline Model 2: Five-factor model, which combines OCB-I and OCB-O & $511.38^{* *}$ & 160 & .10 & .07 & .91 & .91 & $273.65^{* *}$ & 5 \\
\hline Model 3: Five-factor model, which combines death anxiety and death reflection & $934.78^{* *}$ & 160 & .14 & .14 & .79 & .80 & $697.05^{* *}$ & 5 \\
\hline $\begin{array}{l}\text { Model 4: Four-factor model, which combines OCB factors and death } \\
\text { awareness factors }\end{array}$ & $1,205.68^{* *}$ & 164 & .16 & .15 & .72 & .72 & $967.95^{* *}$ & 9 \\
\hline Model 5: One-factor model, which combines all variables & $2,788.84^{* *}$ & 170 & .25 & .29 & .30 & .31 & $2,551.11^{* *}$ & 15 \\
\hline
\end{tabular}

Note. $N=241$ employees. $\chi^{2}=$ maximum likelihood ratio chi-square. $d f$ degrees of freedom. $R M S E A$ root mean square error of approximation, $S R M R$ standardized root mean square residual, $C F I$ comparative fit index, $I F I$ incremental fit index, $O C B-I$ organizational citizenship behavior directed at individuals, $O C B-O$ organizational citizenship behavior directed at the organization *** $p<.01$ 
Table 2 Descriptive statistics and intercorrelations between study variables
Fig. 2 Hierarchical regression results of proposed model. $N=241$ employees. DA = death anxiety. $\mathrm{DR}=$ death reflection. $\mathrm{OI}=$ organizational identification. OCB-I = organizational citizenship behavior directed at individuals. OCB-O = organizational citizenship behavior directed at the organization. The estimates reported are standardized coefficients. Coefficients in parentheses are standardized coefficients after controlling prosocial motivation. Bold lines represent significant relationships. Dashed lines represent relationships that are not significant. For the sake of clarity, this figure only includes the main study variables and proposed relationships. For full results, see Tables 3 and $4 .{ }^{*} p \leq .05$. $* * p \leq .01$

\begin{tabular}{llllllllllll}
\hline Variable & $M$ & $S D$ & 1 & 2 & 3 & 4 & 5 & 6 & 7 & 8 & 9 \\
\hline 1. Age & 4.57 & 1.20 & & & & & & & & & \\
2. NA & 1.78 & .68 & $-.30^{* *}$ & $(.91)$ & & & & & & & \\
3. Sex & 1.40 & .49 & -.06 & -.03 & & & & & & & \\
4. Death Anxiety & 3.36 & 1.73 & -.08 & .07 & -.12 & $(.95)$ & & & & & \\
5. Death Reflection & 3.39 & .71 & -.06 & $.19^{* *}$ & -.06 & $.35^{* *}$ & $(.90)$ & & & & \\
6. OI & 4.28 & 1.41 & $.15^{*}$ & -.10 & -.12 & .08 & $.21^{* *}$ & $(.89)$ & & & \\
7. Prosocial Motivation & 5.75 & .85 & -.03 & -.05 & $-.31^{* *}$ & -.05 & $.20^{* *}$ & $.32^{* *}$ & $(.93)$ & & \\
8. OCB-I & 3.39 & .73 & -.06 & .02 & $-.15^{*}$ & -.05 & $.23^{* *}$ & $.25^{* *}$ & $.30^{* *}$ & $(.87)$ & \\
9. OCB-O & 2.90 & .94 & .08 & -.08 & -.11 & -.06 & $.20^{* *}$ & $.49^{* *}$ & $.32^{* *}$ & $.58^{* *}$ & $(.90)$ \\
\hline
\end{tabular}

Note. $N=241$ employees. Internal consistency reliabilities are reported along the diagonals in parentheses. Sex is a categorical variable $(1=$ male; $2=$ female). $N A$ negative affectivity, $O I$ organizational identification, $O C B-I$ organizational citizenship behavior directed at individuals, $O C B-O$ organizational citizenship behavior directed at the organization ${ }^{*} p \leq .05 .{ }^{* *} p \leq .01$

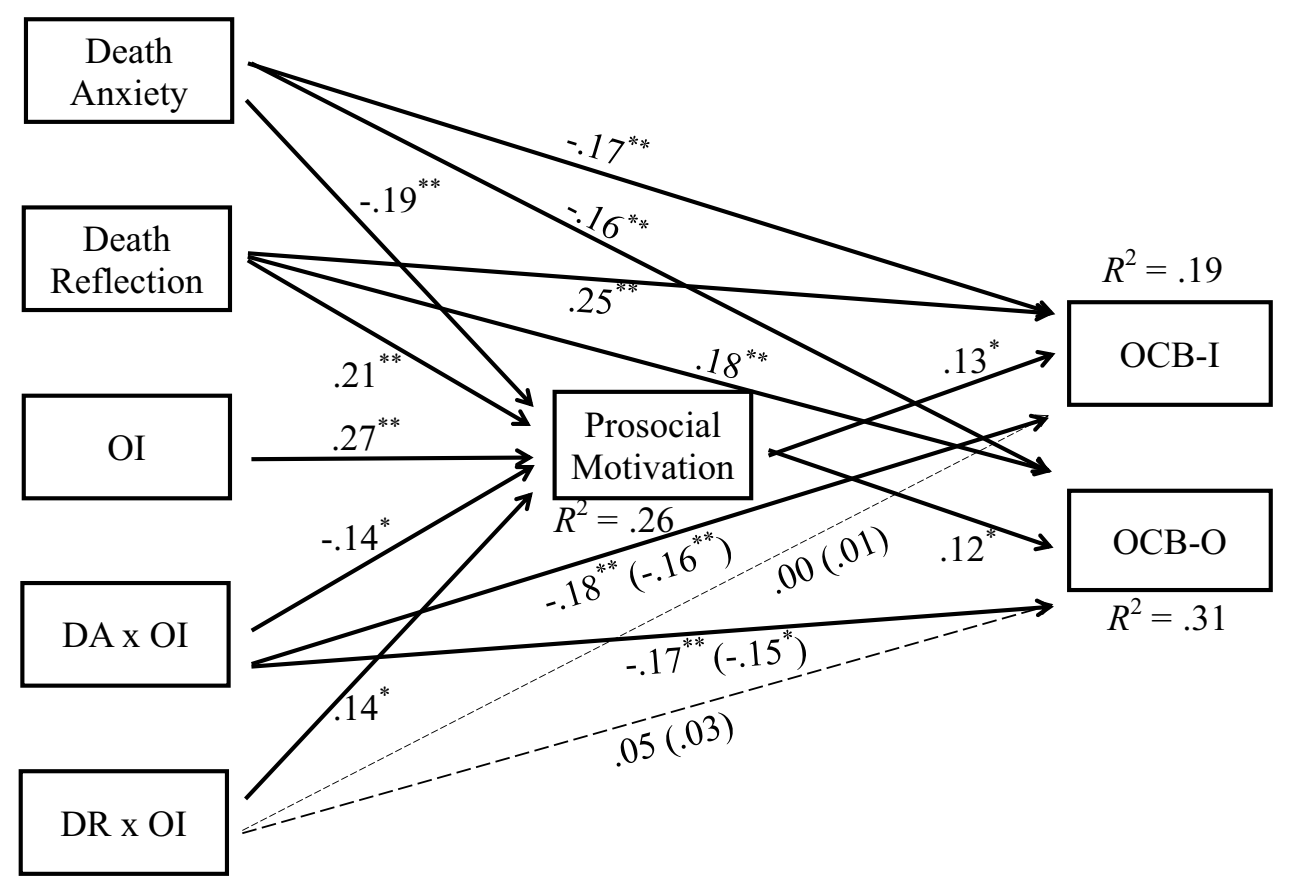

Before testing indirect effects, we examined the direct relationships between the study variables. As shown in Table 3, death anxiety was negatively related to prosocial motivation after controlling age, sex, NA, and OI $(\beta=-.19$, $p<.01)$. Death reflection was positively related to prosocial motivation after controlling age, sex, NA, and OI ( $\beta=.21$, $p<.01$ ). As for moderation, the interaction of death anxiety and OI was negatively related to prosocial motivation after controlling age, sex, NA, death anxiety, death reflection, and OI $(\beta=-.14, p=.05)$. Figure 3 graphs the interaction, showing that death anxiety was more negatively related to prosocial motivation when OI was lower $(\beta=-.35$, $t=-3.60, p<.01)$ than when OI was higher $(\beta=-.05$, $t=-.55, p=.58)$. The interaction of death reflection and OI, however, was positively related to prosocial motivation after controlling age, sex, NA, death anxiety, death reflection, and OI ( $\beta=.14, p=.03)$. Figure 4 graphs the interaction, showing that death reflection was more positively related to prosocial motivation when OI was lower $(\beta=.38$, $t=3.92, p<.001)$ than when OI was higher $(\beta=.11, t=.99$, $p=.32$ ). As reported in Table 4, prosocial motivation was positively related to OCB-I ( $\beta=.13, p=.03)$ and OCB-O ( $\beta=.12, p=.04)$ after controlling age, sex, NA, death anxiety, death reflection, OI, and the interaction terms.

We followed Edwards and Lambert's (2007) recommendations for testing partial mediation and partial moderated mediation by conducting a path analysis in LISREL. We used 1,000 bootstrap samples to compute $95 \%$ bias-corrected confidence intervals. The results for the path analyses can be seen in Table 5. In regard to mediation, the negative relationship 
Table 3 Hierarchical regression of prosocial motivation on study variables

\begin{tabular}{|c|c|c|c|c|c|c|}
\hline \multirow[b]{3}{*}{ Variable } & \multicolumn{6}{|c|}{ Prosocial motivation } \\
\hline & \multicolumn{2}{|c|}{ Model 1} & \multicolumn{2}{|l|}{ Model 2} & \multicolumn{2}{|l|}{ Model 3} \\
\hline & $\beta$ & $S E$ & $\beta$ & $S E$ & $\beta$ & $S E$ \\
\hline \multicolumn{7}{|l|}{ Control variable } \\
\hline Age & -.08 & .05 & $-.13^{*}$ & .04 & $-.12^{*}$ & .04 \\
\hline NA & -.09 & .08 & -.10 & .08 & -.11 & .08 \\
\hline Sex & $-.32^{* *}$ & .11 & $-.30^{* *}$ & .10 & $-.31^{* *}$ & .10 \\
\hline \multicolumn{7}{|c|}{ Independent variable } \\
\hline Death anxiety & & & $-.19^{* *}$ & .03 & $-.19^{* *}$ & .09 \\
\hline Death reflection & & & $.21^{* *}$ & .08 & $.21^{* *}$ & .22 \\
\hline \multicolumn{7}{|l|}{ Moderator } \\
\hline OI & & & $.26^{* *}$ & .04 & $.27^{* *}$ & .16 \\
\hline \multicolumn{7}{|l|}{ Interaction term } \\
\hline $\mathrm{DA} \times \mathrm{OI}$ & & & & & $-.14^{*}$ & .02 \\
\hline $\mathrm{DR} \times \mathrm{OI}$ & & & & & $.14^{*}$ & .05 \\
\hline$R^{2}$ & $.11^{* *}$ & & $.24^{* *}$ & $.26^{* *}$ & & \\
\hline$\Delta R^{2}$ & & & $.13^{* *}$ & $.02^{*}$ & & \\
\hline
\end{tabular}

Note. $N=241$ employees. $D A$ death anxiety, $D R$ death reflection, $N A$ negative affectivity, $O I$ organizational identification

${ }^{*} p \leq .05 .{ }^{*} p \leq .01$

Table 4 Hierarchical regression of OCB-I and OCB-O on study variables

\begin{tabular}{|c|c|c|c|c|c|c|c|c|c|c|c|c|}
\hline \multirow[t]{3}{*}{ Variable } & \multicolumn{6}{|l|}{ OCB-I } & \multicolumn{6}{|l|}{ OCB-O } \\
\hline & \multicolumn{2}{|c|}{ Model 4} & \multicolumn{2}{|l|}{ Model 5} & \multicolumn{2}{|c|}{ Model 6} & \multicolumn{2}{|l|}{ Model 7} & \multicolumn{2}{|c|}{ Model 8} & \multicolumn{2}{|c|}{ Model 9} \\
\hline & $\beta$ & $S E$ & $\beta$ & $S E$ & $\beta$ & $S E$ & $\beta$ & $S E$ & $\beta$ & $S E$ & $\beta$ & $S E$ \\
\hline \multicolumn{13}{|l|}{ Control variable } \\
\hline Age & -.11 & .04 & -.10 & .04 & -.09 & .04 & -.01 & .05 & .00 & .05 & .01 & .05 \\
\hline NA & -.03 & .07 & -.05 & .07 & -.04 & .07 & -.06 & .08 & -.07 & .08 & -.06 & .08 \\
\hline Sex & $-.14^{*}$ & .09 & $-.15^{*}$ & .09 & -.11 & .10 & -.06 & .11 & -.07 & .11 & -.04 & .11 \\
\hline \multicolumn{13}{|l|}{ Independent variable } \\
\hline Death anxiety & $-.17^{* *}$ & .03 & $-.17^{* *}$ & .08 & $-.15^{*}$ & .08 & $-.16^{* *}$ & .03 & $-.16^{* *}$ & .10 & $-.13^{*}$ & .10 \\
\hline Death reflection & $.24^{* *}$ & .07 & $.25^{* *}$ & .21 & $.23^{* *}$ & .21 & $.17^{* *}$ & .08 & $.18^{* *}$ & .24 & $.15^{*}$ & .25 \\
\hline \multicolumn{13}{|l|}{ Moderator } \\
\hline OI & $.21^{* *}$ & .03 & $.21^{* *}$ & .15 & $.18^{* *}$ & .15 & $.45^{* *}$ & .04 & $.45^{* *}$ & .17 & $.41^{* * *}$ & .17 \\
\hline \multicolumn{13}{|l|}{ Interaction term } \\
\hline $\mathrm{DA} \times \mathrm{OI}$ & & & $-.18^{* * *}$ & .02 & $-.16^{* *}$ & .02 & & & $-.17^{* *}$ & .02 & $-.15^{*}$ & .02 \\
\hline $\mathrm{DR} \times \mathrm{OI}$ & & & .00 & .05 & .01 & .05 & & & .05 & .05 & .03 & .05 \\
\hline \multicolumn{13}{|l|}{ Mediator } \\
\hline Prosocial motivation & & & & & $.13^{*}$ & .06 & & & & & $.12^{*}$ & .07 \\
\hline$R^{2}$ & $.14^{* *}$ & & $.17^{* *}$ & & $.19^{* *}$ & & $.27^{* *}$ & & $.29^{* *}$ & & $.31^{* *}$ & \\
\hline$\Delta R^{2}$ & & & $.03^{*}$ & & $.02^{*}$ & & & & $.02^{*}$ & & $.02^{*}$ & \\
\hline
\end{tabular}

Note. $N=241$ employees. $D A$ death anxiety, $D R$ death reflection, $N A$ negative affectivity, $O I$ organizational identification, $O C B-I$ organizational citizenship behavior directed at individuals, $O C B-O$ organizational citizenship behavior directed at the organization

${ }^{*} p \leq .05$. ${ }^{* *} p \leq .01$

between death anxiety and OCB-I was mediated by prosocial motivation $(B=-.02,95 \% \mathrm{CI}[-.04,-.00])$ as was the negative relationship between death anxiety and OCB-O $(B=-.03$,
95\% CI [-.05, - .01]). The positive relationship between death reflection and OCB-I was also mediated by prosocial motivation $(B=.07$, CI $[.02, .11])$ as was the positive relationship 


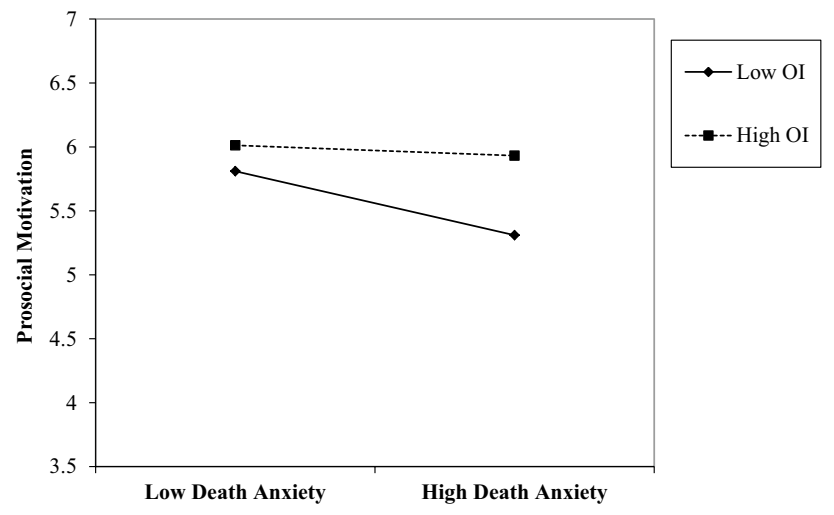

Fig. 3 Interaction of death anxiety and OI predicting prosocial motivation. $\mathrm{OI}=$ organizational identification. The effects of death anxiety on prosocial motivation at low and high levels of OI. Low $\mathrm{OI}=1$ standard deviation below the mean. High $\mathrm{OI}=1$ standard deviation above the mean

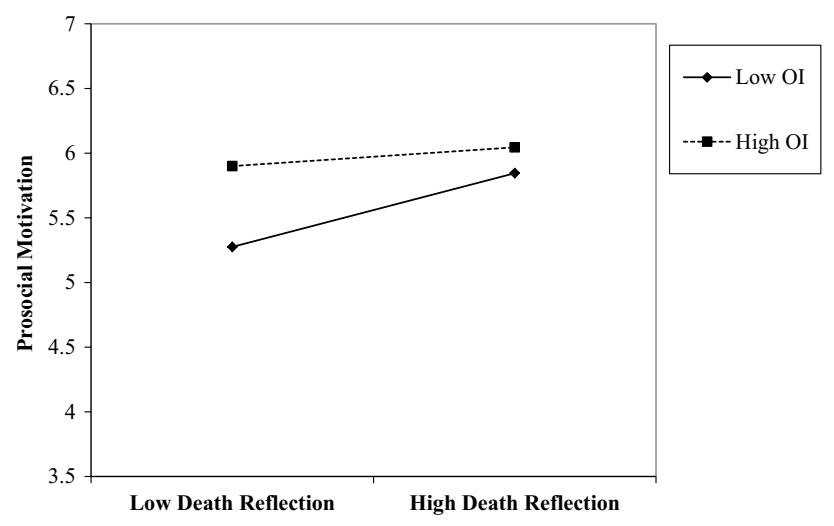

Fig. 4 Interaction of death reflection and OI predicting prosocial motivation. OI= organizational identification. The effects of death reflection on prosocial motivation at low and high levels of OI. Low $\mathrm{OI}=1$ standard deviation below the mean. High $\mathrm{OI}=1$ standard deviation above the mean

between death reflection and OCB-O $(B=.10$, CI $[.04, .16])$. Therefore, Hypotheses $3 \mathrm{a}$ through $4 \mathrm{~b}$ were supported.

For moderated mediation, the indirect effect of death anxiety on OCB-I through prosocial motivation was significant when OI was lower $(B=-.05$, CI $[-.10,-.01])$, but was not significant when OI was higher $(B=.02$, CI $[-.04$, $.08])$. The indirect effect of death anxiety on OCB-O through prosocial motivation was significant when OI was lower $(B=-.05$, CI $[-.09,-.00])$, but was not significant when OI was higher $(B=.04, \mathrm{CI}[-.06, .13])$. The indirect effect of death reflection on OCB-I through prosocial motivation was not significant when OI was lower $(B=.01$, CI [ -.11 , $.12])$ or higher $(B=.08, \mathrm{CI}[-.07, .22])$. Lastly, the indirect effect of death reflection on OCB-O through prosocial motivation was not significant when OI was lower $(B=.01, \mathrm{CI}$ $[-.09, .10])$ or higher $(B=.12$, CI $[-.09, .34])$. Thus, there is support for Hypotheses $5 \mathrm{a}$ and $5 \mathrm{~b}$, but not for Hypotheses $6 \mathrm{a}$ and $6 \mathrm{~b}$.

\section{Discussion}

Employees can be naturally inclined to think about and be emotionally affected by death. The purpose of the present study was to understand when and why these cognitive and affective approaches to death influence employees' work motivation and helping behavior. Specifically, we examined prosocial motivation as a potential reason for why employees who are aware of death engage in helping behavior, with OI as a potential boundary condition of this proposed indirect relationship. We found general support for our model and in doing so we were able to provide construct validity evidence that distinguishes death anxiety from death reflection.

Despite the empirical evidence supporting our model, it is worth pointing out that death anxiety was not significantly correlated with prosocial motivation $(r=-.05, p=.39)$, OCB-I $(r=-.05, p=.39)$, or OCB-O $(r=-.06, p=.34)$ when the controls and death reflection were not included in the model. This raises some questions regarding the conclusions drawn about our findings, specifically, if support for Hypothesis 1 is dependent on additional variables being included in the model. We are inclined to believe that the inclusion of death reflection may have contributed to these differences in findings, and post hoc analyses seem to provide some support for this conjecture. Death anxiety was significantly related to OCB-I $(\beta=-.15, p=.03)$ and OCB-O $(\beta=-.15, p=.03)$ when the model only included death reflection. Given the conceptual overlap between death anxiety and death reflection, it is somewhat expected that there would be overlap in variance among these constructs. As Table 2 shows, death reflection was the only variable in the model that was significantly correlated with death anxiety. These two variables are likely to be closely related both as constructs and in the timing of their occurrence. Putting death reflection into the equation with death anxiety may have helped to control the overlap between the two variables, so that the beta presented a truer estimate of the unique effects of death anxiety without possible contamination by death reflection. It is for this reason that we strongly encourage organizational researchers to consider measuring death anxiety and death reflection simultaneously, so that their unique effects can be observed.

To further strengthen the conclusions drawn from this study, we conducted four alternative model tests to check for robustness. These alternative models tested four potential interactions between death anxiety, death reflection, and select control variables (i.e., NA and age), which have been conceptually or empirically explored (e.g., Arndt \& Solomon, 2003; Frias et al., 2011; Grant \& Wade-Benzoni, 
Table 5 Moderated mediation analyses of death anxiety and death reflection on OCB through prosocial motivation

\begin{tabular}{llllll}
\hline Independent variable & Dependent variable & $\begin{array}{l}\text { Moderator } \\
(\mathrm{OI})\end{array}$ & $\begin{array}{l}\text { Indirect } \\
\text { effect }\end{array}$ & $S E$ & $\begin{array}{l}95 \% \text { bias-cor- } \\
\text { rected bootstrap } \\
\text { CI }\end{array}$ \\
\hline Death anxiety & OCB-I & - & $-.02^{*}$ & .01 & {$[-.035,-.003]$} \\
Death anxiety & OCB-I & Low & $-.05^{*}$ & .02 & {$[-.101,-.007]$} \\
Death anxiety & OCB-I & High & .02 & .03 & {$[-.039, .083]$} \\
Death reflection & OCB-I & - & $.07^{*}$ & .02 & {$[.022, .112]$} \\
Death aeflection & OCB-I & Low & .01 & .06 & {$[-.108, .120]$} \\
Death reflection & OCB-I & High & .08 & .07 & {$[-.067, .219]$} \\
Death anxiety & OCB-O & - & $-.03^{*}$ & .01 & {$[-.050,-.006]$} \\
Death anxiety & OCB-O & Low & $-.05^{*}$ & .02 & {$[-.090,-.004]$} \\
Death anxiety & OCB-O & High & .04 & .05 & {$[-.056, .128]$} \\
Death reflection & OCB-O & - & $.10^{*}$ & .03 & {$[.036, .162]$} \\
Death reflection & OCB-O & Low & .01 & .05 & {$[-.092, .104]$} \\
Death reflection & OCB-O & High & .12 & .11 & {$[-.093, .335]$} \\
\hline
\end{tabular}

Note. $N=241$ employees. Partial moderated mediation was tested. $N A$ negative affectivity, $O I$ organizational identification, $O C B-I$ organizational citizenship behavior directed at individuals, $O C B-O$ organizational citizenship behavior directed at the organization. Age, NA, and sex were included as control variables in the analyses. Coefficients of the indirect effects are unstandardized. Number of repeated bootstrap samples $=1,000$. We used a median-split method to test moderated mediation. Low $=$ below the median. High $=$ above the median. $-=$ a separate path analysis was conducted without the moderator to test partial mediation

${ }^{*} p \leq .05$
2009; Maxfield et al., 2007). Overall, there were no significant changes to the results that altered the focal conclusions drawn from this study. For full results of the robustness checks, see Appendix 21.

\section{Theoretical Implications}

The current study advances the organizational literature in several ways. First, our findings advance the literature by being one of the few studies to examine death anxiety and death reflection concurrently, showing their effects were unique. Prior research has examined death anxiety and death reflection separately, raising concerns of the distinctiveness of death anxiety and death reflection (Cozzolino et al., 2004; Jonas et al., 2002; Pyszczynski et al., 2003). Hence, we examined both constructs simultaneously to clarify the relationships these constructs have to other variables. The results suggest employees experiencing death reflection are more prosocially motivated to engage in OCB, whereas employees experiencing death anxiety are less likely to engage in OCB because of their lack of prosocial motivation. Therefore, this research is important because it advances our knowledge about death awareness, providing a clear distinction between the effects of death anxiety and death reflection on important workplace behavior.

Secondly, the current study also makes an important contribution to the organizational literature by identifying OI as an important boundary condition of the potential effects of death anxiety and death reflection on prosocial motivation in the workplace. TMT and PTG theory heavily focus on the influence of worldviews and assumptive worlds on an individual's motivation and behavior (Greenberg et al., 1986; Janoff-Bulman, 1992; Tedeschi \& Calhoun, 2004), but research has mainly operationalized these worldviews and assumptive worlds in terms of demographic variables, such as race, religion, or country of origin. However, our findings suggest that employees' identification with the organization can greatly influence the relationships of employees' death anxiety and death reflection with their work motivation and helping behavior. Specifically, an employee's prosocial motivation and subsequent engagement in OCB depends jointly on whether an individual identifies with the organization and the extent to which an employee experiences death-related anxiety. Therefore, these findings are important because they broaden the scope of domains in which employees can identify and outline circumstances in which employees who are anxious about death become motivated.

Lastly, these findings expand the organizational literature by identifying death anxiety and death reflection as important predictors of workplace behavior. Prior research has primarily assessed death anxiety and death reflection in a laboratory setting with students, which raises questions about the applicability of the findings to employees and the workplace. Based on the results of this study, it is evident that death anxiety and death reflection can affect how employees act in the workplace. Thus, this research is important because it emphasizes the importance of understanding the effects of death awareness in the workplace. 
Further, this research demonstrates that even employees in non-death-related jobs, which characterize most of the present sample, are susceptible to the effects imposed by death anxiety and death reflection.

\section{Limitations and Future Research Directions}

Despite these promising findings, there are some limitations that need to be recognized. First, although the study conducted a three-wave time-lagged model to reduce common method effects (e.g., Podsakoff et al., 2012), we were not able to establish strong inferences about causality. Future research could improve on this by instituting experimental or quasi-experimental designs (e.g., Cook et al., 1990). CMV probably did not have strong effects on the results, however, for multiple reasons. Besides reducing CMV effects by measuring the variables at different points in time, one of the control variables, NA, was measured using the same method as the variables in the model, which should help control for its method (similar to effects of a marker variable recommended by Podsakoff et al., 2012) while also controlling for its substantive construct (NA). In addition, some of the key analyses were interaction effects, which have been shown to be immune to common method effects (Siemsen et al., 2010). Future research could address the CMV issues even further by also having other sources rate employee behavior (e.g., supervisor, peer, spouse).

Second, this study did not control for autoregressive effects. Although this study obtained measures at three time points with one-month intervals in between, and research provides support for theory on death anxiety and death reflection influencing prosocial motivation (Greenberg et al., 1986; Lambert et al., 2014; Tedeschi \& Calhoun, 1996; Wrzesniewski, 2002) and prosocial motivation influencing OCBs (Grant, 2008; Grant \& Mayer, 2009; Meglino \& Korsgaard, 2004; Rioux \& Penner, 2001), we cannot make strong inferences about the causality or directionality of these relationships. Future research can address this issue by conducting a cross-lagged panel research design where each variable is measured at different time points.

Third, there may be concerns about the conclusions drawn from this study considering the sample size and sample demographics. Although some statistical rule of thumbs suggest that the sample size is more than adequate to test our model (Bentler \& Chou, 1987; Nunnally, 1967), the moderation effects may lack sufficient statistical power and have small effect sizes (Murphy \& Russell, 2016). As for the sample demographics, this study assessed employees whose jobs may have low exposure to death rather than high exposure to death. This is reflected in the sample demographics, which found at least $81 \%$ of participants to be in low-exposure jobs $(n=194$; e.g., advertising and marketing, business support and logistics, education). This does, however, highlight the relevance of examining death anxiety and death reflection across a variety of jobs, not just those with high exposure to death. Nonetheless, future research could assess mortality salience in other, larger samples that are more often exposed to death (e.g., military soldiers, police officers) to strengthen the conclusions drawn from this study and generalize the results further.

There are also several directions for future research worth noting, given that death awareness is an obscure area in the organizational literature. For instance, there have been some criticisms regarding the robustness of PTG findings and the empirical inconsistencies of TMT findings (Hart, 2014; Klein et al., 2019). Although researchers have suggested that this may be a result of studies having insufficient power (Chatard et al., 2020), study design and manipulations of death may also be contributing factors (Infurna \& Jayawickreme, 2019). Death is a powerful force, which makes it difficult to recreate in an experimental setting. One of the reasons why we are seeing issues in these areas of research may be because researchers have not been able to find a design that can accurately manipulate these psychological threats (Cox et al., 2019). In addition, studies conducted in a laboratory setting are not able to establish external and construct validity evidence. This suggests that there are several major areas that need to be addressed in the TMT and PTG literature. We propose that the best way to approach these issues is by using a mix of research designs and instruments when examining death anxiety and death reflection in the workplace. As mentioned earlier, organizational researchers can address many of these issues by using a quasi-experimental research design, which is great for observing naturally occurring moments of death in a way that is more ethical and feasible to do in the workplace as well as establishing some much needed external validity evidence (Cook et al., 1990). Additionally, the construct validity evidence we established in this study is only a snapshot of the work-related behavioral outcomes death anxiety and death reflection may be associated with, so we highly encourage researchers to continue to use the death anxiety and death reflection scales to simultaneously examine the effects of these constructs on other behavioral outcomes.

Researchers should also investigate other potential moderators of the relationship between death anxiety and prosocial motivation. According to TMT, self-esteem can buffer the harmful effects of death anxiety (Greenberg et al., 1986). Thus, we encourage researchers to examine self-esteem along with OI to see if these variables independently moderate the relationship between death anxiety and prosocial motivation.

Researchers should also consider other types of work motivation to explain why death anxiety and death reflection could affect employee behavior. It would be particularly interesting to explore other underlying motives for death anxiety, such as a self-oriented motive or extrinsic motivation, considering that death anxiety was negatively related to 
prosocial motivation. Research shows that people with death anxiety are more likely to engage in helping behavior when they can personally benefit from the results of their actions (Jonas et al., 2002). These individuals are more likely to have stronger desires to be physically attractive and wealthy (Arndt et al., 2004). These individuals are also more likely to use self-protective responses to defend against their existential anxiety (Arndt et al., 2005; Grant \& Wade-Benzoni, 2009; McGregor et al., 1998). This research suggests that there may be other underlying motives for death anxiety and warrants future exploration from researchers.

Lastly, with the occurrence of the COVID-19 pandemic, researchers are presented with an opportunity to directly observe how mortality salience and death awareness influence employee and organizational outcomes. It would be interesting for researchers to replicate this study to see how results differ before and after the pandemic occurred. It is during times like these that employees, especially those high in OI, are going to be heavily reliant on supervisors and organizations to provide guidance and stability. Additionally, exposure to mortality cues has been found to increase death anxiety and death reflection (Jacobsen \& Beehr, 2018). As a result, employees have reported engaging in more prosocial behavior following a traumatic event (Wrzesniewski, 2002). Given the influence mortality salience can have on death anxiety, death reflection, and employee behavior, it is likely that the relationships in our proposed model will be stronger because of the pandemic.

\section{Practical Implications}

Findings from the current study suggest that death reflection prosocially drives employees to engage in desirable work behavior. Considering these results, organizations need to be cognizant of and actively seeking ways to promote employees to engage in death reflection rather than death anxiety when mortality cues arise. Death reflection is a cognitive process that requires employees to review, contemplate, and take perspective on their life (Cozzolino et al., 2004). On the other hand, death anxiety is an emotional process that heightens employees' fears and anxieties when faced with death (Nyatanga \& de Vocht, 2006). Therefore, it is important for organizations to invest in interventions that provide employees with tools to reflect upon themselves, especially if a death-related event is likely to occur in the workplace. This is especially true for organizations where employees are chronically exposed to death, such as death of a client or working in a high-risk country (Grant \& Wade-Benzoni, 2009; Jacobsen \& Beehr, 2020a, 2020b). That way, in case a mortality cue occurs, even under the radar of the organization, the employees will have the tools needed to overcome the event and experience the more positive effects.
Furthermore, organizations could provide additional training opportunities for supervisors to learn how to promote employee reflection on death, or at least to not discourage it. For jobs where encounters with deaths or near-deaths are likely, supervisors should also learn how to detect behavioral signs that employees are becoming anxious rather than reflecting on their death after experiencing mortality cues. In certain countries, particularly in the West, talking about and even thinking about death may be seen as a taboo (Nyatanga $\&$ de Vocht, 2006). This is concerning because employees who do not reflect on their death are less prosocially motivated and thus less likely to proactively assist the organization and its members. To prevent this, supervisors need to encourage employees to reflect on their death or to utilize the services offered by the organization. In cases where employees may be experiencing death anxiety, supervisors need to attentively watch these employees to determine if they show decreases in prosocial motivation. Some examples of these signs include not wanting to work on tasks that could help other colleagues and not being energized when working on tasks that could help other organizational members (Grant \& Sumanth, 2009).

\section{Conclusion}

The purpose of this research was to develop and test a theoretical model of death anxiety and death reflection predicting employee motivation and work behavior. In doing so, these findings identified clear distinctions between death anxiety and death reflection that have been largely unexplored in the organizational literature. We hope the findings from this study offer new insights and inspire scholars and practitioners to consider the dark, and yet intriguingly optimistic effects that death awareness can have on employees and the organization.

\section{Appendix 1. Items Used to Measure Death Anxiety}

This document contains the items used to measure death anxiety. Table 6 reports the corrected item-total correlations (CITC) for two samples. The first data collection effort was collected from 175 undergraduate students across 2 time points, of which death anxiety was measured at Time 2 . In the second data collection effort, data was collected from 163 employees across 4 time points, of which death anxiety was measured at Time 1 . 
Table 6 Death anxiety items. Instructions: Indicate the extent to which you agree with each of the following statements

\begin{tabular}{lll}
\hline & \multicolumn{2}{l}{$\begin{array}{l}\text { Corrected item-total correlations } \\
\text { (CITC) }\end{array}$} \\
\cline { 2 - 3 } Items & $\begin{array}{l}\text { Sample 1: } \\
\text { Sndergraduates }\end{array}$ & Employees \\
\hline 1. Not knowing what the next world is like troubles me. & .62 & .75 \\
2. The idea of never thinking again after I die frightens me. & .67 & .68 \\
3. Being totally immobile after death bothers me. & .77 & .79 \\
4. The subject of life after death troubles me greatly. & .73 & .72 \\
5. I hate the idea that I will be helpless after I die. & .70 & .79 \\
6. Never feeling anything again after I die upsets me. & .65 & .72 \\
7. I am troubled by the thought that my body will decompose in the grave. & .65 & .70 \\
8. I am worried about what happens to us after we die. & .71 & .75 \\
9. The total isolation of death is frightening to me. & .77 & .82 \\
\hline
\end{tabular}

\section{Appendix 2. Items Used to Measure Death Reflection}

This document contains the items used to measure death reflection. Table 7 reports the corrected item-total correlations (CITC) for three samples. The first data collection effort was collected from 175 undergraduate students across
2 time points, of which death reflection was measured at Time 2. In the second data collection effort, data was collected from 163 employees across 4 time points, of which death reflection was measured at Time 1 . The third data collection effort was cross-sectional and consisted of 192 adults.
Table 7 Death reflection items. Instructions: How often have you thought about and reflected on the following things, regarding your own death?

\begin{tabular}{llll}
\hline & \multicolumn{3}{l}{ Corrected item-total correlations (CITC) } \\
\cline { 2 - 4 } Items & $\begin{array}{l}\text { Sample 1: } \\
\text { Undergraduates }\end{array}$ & $\begin{array}{l}\text { Sample 2: } \\
\text { Employees }\end{array}$ & \multicolumn{1}{l}{ Sample 3: } \\
& & .62 & .65 \\
\hline 1. I think about the life choices I have made. & .68 & .64 & .69 \\
2. I think about my actions throughout life. & .70 & .62 & .64 \\
3. I think about the reasons why I did certain things in the past. & .64 & .68 & .60 \\
4. I think about the meaning of my life. & .75 & .66 & .61 \\
5. I think about what makes my life significant. & .69 & .70 & .66 \\
6. I think about whether I have lived a meaningful life. & .70 & .65 & .65 \\
7. I think about the reason for my existence. & .71 & .67 & .61 \\
8. I think about how my life fits into the grand scheme of things. & .71 & .64 & .65
\end{tabular}




\section{Appendix 3. Alternative Model Testing}

To examine the robustness of the results found in this study, we conducted four alternative model tests. These alternative models were determined by searching through the existing literature for empirical studies that have examined interactions among the study and control variables. We discovered that studies have examined the interaction between mortality salience and neuroticism (e.g., Arndt \& Solomon, 2003; Goldenberg et al., 2006; Xu \& Brucks, 2011). Given that neuroticism shares some similarities to negative affectivity (i.e., NA), we believe that NA may function similarly as neuroticism and thus examined the interaction between death anxiety and NA. The interaction of mortality salience and age has also been explored (Maxfield et al., 2007; Roberts \& Maxfield, 2019), so we also examined the interaction between death anxiety and age. In addition, research suggests that age plays a major role in how individuals' psychological reactions to death shift over time from anxiety to reflection (Lykins, Segerstrom, Averill, Evans, \& Kemeny, 2007). Although it has not been explored to our knowledge, it has been proposed that future research should explore the moderating role of age on the relationship between death reflection and behavior (Frias et al., 2011). Therefore, we also examine the interaction between death reflection and age. Lastly, we also considered the interaction between death anxiety and death reflection. This is because these constructs share similar functions to the hot and cool systems (Grant \& Wade-Benzoni, 2009), which have been proposed to interact with each other (Metcalfe \& Mischel, 1999). Results for these analyses are reported in Tables 8, 9, 10, and 11. As shown in these tables, there were no significant changes to the results that altered the focal conclusions drawn from this study.
Table 8 Alternative model 1: controlling for the interaction between death anxiety and negative affectivity

\begin{tabular}{|c|c|c|c|c|c|c|c|c|c|c|}
\hline \multirow[b]{3}{*}{ Variable } & \multirow{2}{*}{\multicolumn{2}{|c|}{$\begin{array}{l}\begin{array}{l}\text { Prosocial } \\
\text { motivation }\end{array} \\
\text { Model } 1\end{array}$}} & \multicolumn{4}{|l|}{ OCBI } & \multicolumn{4}{|l|}{ OCB-O } \\
\hline & & & \multicolumn{2}{|l|}{ Model 2} & \multicolumn{2}{|c|}{ Model 3} & \multicolumn{2}{|l|}{ Model 4} & \multicolumn{2}{|c|}{ Model 5} \\
\hline & $\beta$ & $S E$ & $\beta$ & $S E$ & $\beta$ & $S E$ & $\beta$ & $S E$ & $\beta$ & $S E$ \\
\hline \multicolumn{11}{|l|}{ Control variable } \\
\hline Age & $-.12^{*}$ & .04 & -10 & .04 & -.08 & .04 & -.01 & .05 & .01 & .05 \\
\hline NA & $-.14^{*}$ & .17 & -.03 & .15 & -.01 & .16 & -.07 & .18 & -.05 & .18 \\
\hline Sex & $-.31^{* *}$ & .10 & $-.15^{*}$ & .09 & -.10 & .10 & -.07 & .11 & -.03 & .11 \\
\hline $\mathrm{DA} \times \mathrm{NA}$ & $.12^{*}$ & .04 & -.09 & .04 & $-.11^{\dagger}$ & .04 & -.04 & .04 & -.05 & .04 \\
\hline \multicolumn{11}{|l|}{ Independent variable } \\
\hline Death anxiety & $-.20^{* *}$ & .12 & $-.17^{* *}$ & .11 & $-.14^{*}$ & .12 & $-.16^{* *}$ & .13 & $-.13^{*}$ & .14 \\
\hline Death reflection & $.22^{* *}$ & .22 & $.25^{* *}$ & .21 & $.22^{* *}$ & .21 & $.18^{* *}$ & .24 & $.15^{*}$ & .25 \\
\hline \multicolumn{11}{|l|}{ Moderator } \\
\hline OI & $.27^{* *}$ & .16 & $.22^{* *}$ & .15 & $.18^{* *}$ & .15 & $.45^{* *}$ & .17 & $.41^{* *}$ & .17 \\
\hline \multicolumn{11}{|l|}{ Interaction term } \\
\hline $\mathrm{DA} \times \mathrm{OI}$ & $-.15^{*}$ & .02 & $-.17^{* *}$ & .02 & $-.15^{*}$ & .02 & $-.16^{* *}$ & .02 & $-.14^{*}$ & .02 \\
\hline $\mathrm{DR} \times \mathrm{OI}$ & $0.14^{*}$ & .05 & .01 & .05 & .02 & .05 & .05 & .05 & .03 & .05 \\
\hline \multicolumn{11}{|l|}{ Mediator } \\
\hline Prosocial motivation & & & & & $.15^{*}$ & .06 & & & $.13^{*}$ & .07 \\
\hline$R^{2}$ & $.27^{* *}$ & & $.17^{* *}$ & & $.19^{* *}$ & & $.30^{* *}$ & & $.31^{* *}$ & \\
\hline
\end{tabular}

$N=241$ employees. $D A$ death anxiety, $D R$ death reflection, $N A$ negative affectivity, $O I$ organizational identification, $O C B-I$ organizational citizenship behavior directed at individuals, $O C B-O$ organizational citizenship behavior directed at the organization

${ }^{\dagger} p \leq 0.10 .{ }^{*} p \leq 0.05 .{ }^{* *} p \leq 0.01$ 
Table 9 Alternative model 2: controlling for the interaction between death anxiety and age

\begin{tabular}{|c|c|c|c|c|c|c|c|c|c|c|}
\hline \multirow[b]{3}{*}{ Variable } & \multirow{2}{*}{\multicolumn{2}{|c|}{$\begin{array}{l}\text { Prosocial } \\
\text { Motivation }\end{array}$}} & \multicolumn{4}{|l|}{ OCBI } & \multicolumn{4}{|l|}{ OCB-O } \\
\hline & & & \multicolumn{2}{|c|}{ Model 7} & \multicolumn{2}{|c|}{ Model 8} & \multicolumn{2}{|c|}{ Model 9} & \multicolumn{2}{|c|}{ Model 10} \\
\hline & $\beta$ & $S E$ & $\beta$ & $S E$ & $\beta$ & $S E$ & $\beta$ & $S E$ & $\beta$ & $S E$ \\
\hline \multicolumn{11}{|l|}{ Control variable } \\
\hline Age & $-.13^{*}$ & .09 & -.10 & .08 & -.09 & .08 & .00 & .10 & .01 & .10 \\
\hline NA & $-.12^{*}$ & .08 & -.05 & .07 & -.03 & .07 & -.07 & .08 & -.06 & .08 \\
\hline Sex & $-.30^{* *}$ & .10 & $-.15^{*}$ & .09 & $-.11^{\dagger}$ & .10 & -.07 & .11 & -.04 & .11 \\
\hline DA $\times$ age & -.09 & .02 & .00 & .02 & .01 & .02 & .03 & .03 & .04 & .03 \\
\hline \multicolumn{11}{|l|}{ Independent variable } \\
\hline Death anxiety & $-.19^{* * *}$ & .13 & $-.17^{* *}$ & .12 & $-.15^{*}$ & .12 & $-.16^{* *}$ & .14 & $-.13^{*}$ & .14 \\
\hline Death reflection & $.21^{* *}$ & .22 & $.25^{* *}$ & .21 & $.23^{* *}$ & .21 & $.18^{* *}$ & .24 & $.15^{*}$ & .25 \\
\hline \multicolumn{11}{|l|}{ Moderator } \\
\hline OI & $.26^{* *}$ & .16 & $.21^{* *}$ & .15 & $.18^{* *}$ & .15 & $.45^{* *}$ & .17 & $.41^{* *}$ & .17 \\
\hline \multicolumn{11}{|l|}{ Interaction term } \\
\hline $\mathrm{DA} \times \mathrm{OI}$ & $-.15^{*}$ & .02 & $-.18^{* *}$ & .02 & $-.16^{*}$ & .02 & $-.16^{* *}$ & .02 & $-.14^{*}$ & .02 \\
\hline $\mathrm{DR} \times \mathrm{OI}$ & $.14^{*}$ & .05 & .00 & .05 & .01 & .05 & .05 & .05 & .03 & .05 \\
\hline \multicolumn{11}{|l|}{ Mediator } \\
\hline Prosocial motivation & & & & & $.13^{\dagger}$ & .06 & & & $.13^{*}$ & .07 \\
\hline$R^{2}$ & $.27^{* *}$ & & $.17^{* *}$ & & $.19^{* *}$ & & $.30^{* *}$ & & $.31^{* * *}$ & \\
\hline
\end{tabular}

$N=241$ employees. $D A$ death anxiety, $D R$ death reflection, $N A$ negative affectivity, $O I$ organizational identification, $O C B-I$ organizational citizenship behavior directed at individuals, $O C B$ - $O$ organizational citizenship behavior directed at the organization

${ }^{\dagger} p \leq 0.10 .{ }^{*} p \leq 0.05 .{ }^{* *} p \leq 0.01$

\begin{tabular}{|c|c|c|c|c|c|c|c|c|c|c|}
\hline \multirow[b]{3}{*}{ Variable } & \multirow{2}{*}{\multicolumn{2}{|c|}{$\begin{array}{l}\begin{array}{l}\text { Prosocial } \\
\text { Motivation }\end{array} \\
\text { Model } 11\end{array}$}} & \multicolumn{4}{|l|}{ OCBI } & \multicolumn{4}{|l|}{ OCB-O } \\
\hline & & & \multicolumn{2}{|c|}{ Model 12} & \multicolumn{2}{|c|}{ Model 13} & \multicolumn{2}{|c|}{ Model 14} & \multicolumn{2}{|c|}{ Model 15} \\
\hline & $\beta$ & $S E$ & $\beta$ & $S E$ & $\beta$ & $S E$ & $\beta$ & $S E$ & $\beta$ & $S E$ \\
\hline \multicolumn{11}{|l|}{ Control variable } \\
\hline Age & $-.12^{*}$ & .22 & -0.10 & 0.20 & -0.09 & .20 & -.01 & .24 & .01 & .24 \\
\hline NA & $-.12^{*}$ & .08 & -0.05 & 0.07 & -0.04 & .07 & -.07 & .08 & -.06 & .08 \\
\hline Sex & $-.30^{*}$ & .10 & $-.15^{*}$ & .09 & $-.11^{\dagger}$ & .10 & -.07 & .11 & -.04 & .11 \\
\hline DR $\times$ age & -.04 & .06 & -.03 & .06 & -.02 & .06 & .02 & .07 & .03 & .07 \\
\hline \multicolumn{11}{|l|}{ Independent variable } \\
\hline Death anxiety & $-.19^{* *}$ & .09 & $-.17^{* *}$ & .08 & $-.15^{*}$ & .08 & $-.16^{* *}$ & .10 & $-.13^{*}$ & .10 \\
\hline Death reflection & $.21^{* *}$ & .33 & $.25^{* *}$ & .30 & $.23^{* *}$ & .30 & $.18^{* *}$ & .35 & $.15^{*}$ & .36 \\
\hline \multicolumn{11}{|l|}{ Moderator } \\
\hline OI & $.27^{* *}$ & .16 & $.21^{* *}$ & .15 & $.18^{* *}$ & .15 & $.45^{* *}$ & .18 & $.41^{* *}$ & .18 \\
\hline \multicolumn{11}{|l|}{ Interaction term } \\
\hline $\mathrm{DA} \times \mathrm{OI}$ & $-.14^{*}$ & .02 & $-.18^{* *}$ & .02 & $-.16^{*}$ & .02 & $-.17^{* *}$ & .02 & $-.15^{*}$ & .02 \\
\hline $\mathrm{DR} \times \mathrm{OI}$ & $.13^{*}$ & .05 & .00 & .05 & .02 & .05 & .05 & .6 & .04 & .06 \\
\hline \multicolumn{11}{|l|}{ Mediator } \\
\hline Prosocial motivation & & & & & $.13^{\dagger}$ & .06 & & & $.13^{*}$ & .07 \\
\hline$R^{2}$ & $.26^{* *}$ & & $.17^{* *}$ & & $.19^{* *}$ & & $.29^{* *}$ & & $.31^{* *}$ & \\
\hline
\end{tabular}

$N=241$ employees. $D A$ death anxiety, $D R$ death reflection, $N A$ negative affectivity, $O I$ organizational identification, $O C B-I$ organizational citizenship behavior directed at individuals, $O C B-O$ organizational citizenship behavior directed at the organization

${ }^{\dagger} p \leq 0.10 .{ }^{*} p \leq 0.05 .{ }^{* *} p \leq 0.01$ 
Table 11 Alternative model 4: controlling for the interaction between death anxiety and death reflection

\begin{tabular}{|c|c|c|c|c|c|c|c|c|c|c|}
\hline \multirow[b]{3}{*}{ Variable } & \multirow{2}{*}{\multicolumn{2}{|c|}{$\begin{array}{l}\begin{array}{l}\text { Prosocial } \\
\text { Motivation }\end{array} \\
\text { Model } 16\end{array}$}} & \multicolumn{4}{|l|}{ OCB-O } & \multicolumn{4}{|l|}{ OCB-O } \\
\hline & & & \multicolumn{2}{|c|}{ Model 17} & \multicolumn{2}{|c|}{ Model 18} & \multicolumn{2}{|c|}{ Model 19} & \multicolumn{2}{|c|}{ Model 20} \\
\hline & $\beta$ & $S E$ & $\beta$ & $S E$ & $\beta$ & $S E$ & $\beta$ & $S E$ & $\beta$ & $S E$ \\
\hline \multicolumn{11}{|l|}{ Control Variable } \\
\hline Age & $-.12^{*}$ & .04 & -.10 & .04 & -.09 & .04 & .00 & .05 & .01 & .05 \\
\hline NA & $-.11^{\dagger}$ & .08 & -.05 & .07 & -.04 & .07 & -.07 & .08 & -.06 & .08 \\
\hline Sex & $-.30^{* * *}$ & .10 & $-.15^{*}$ & .09 & $-.11^{\dagger}$ & .10 & -.07 & .11 & -.03 & .11 \\
\hline $\mathrm{DA} \times \mathrm{DR}$ & $-.14^{*}$ & .04 & -.04 & .04 & -.02 & .04 & -.04 & .04 & -.02 & .04 \\
\hline \multicolumn{11}{|c|}{ Independent variable } \\
\hline Death anxiety & $-.13^{*}$ & .16 & $-.16^{*}$ & .15 & $-.14^{*}$ & .15 & $-.14^{*}$ & .18 & $-.13^{*}$ & .18 \\
\hline Death reflection & $.22^{* *}$ & .25 & $.26^{* *}$ & .23 & $.23^{* *}$ & .24 & $.18^{* *}$ & .27 & $.15^{* *}$ & .28 \\
\hline \multicolumn{11}{|l|}{ Moderator } \\
\hline OI & $.25^{* *}$ & .16 & $.21^{* * *}$ & .15 & $.18^{* * *}$ & .15 & $.44^{* *}$ & .18 & $.41^{* *}$ & .18 \\
\hline \multicolumn{11}{|l|}{ Interaction term } \\
\hline $\mathrm{DA} \times \mathrm{OI}$ & $-.16^{* *}$ & .02 & $-.19^{* *}$ & .02 & $-.17^{* *}$ & .02 & $-.17^{* *}$ & .02 & $-.15^{* *}$ & .02 \\
\hline $\mathrm{DR} \times \mathrm{OI}$ & $.12^{*}$ & .05 & .00 & .05 & .02 & .05 & .04 & .05 & .03 & .05 \\
\hline \multicolumn{11}{|l|}{ Mediator } \\
\hline $\begin{array}{l}\text { Prosocial motiva- } \\
\text { tion }\end{array}$ & & & & & $.13^{\dagger}$ & .06 & & & $.12^{\dagger}$ & .07 \\
\hline$R^{2}$ & $.28^{* *}$ & & $.17^{* *}$ & & $.19^{* *}$ & & $.30^{* *}$ & & $.31^{* *}$ & \\
\hline
\end{tabular}

$N=241$ employees. $D A$ death anxiety, $D R$ death reflection, $N A$ negative affectivity, $O I$ organizational identification, $O C B-I$ organizational citizenship behavior directed at individuals, $O C B-O$ organizational citizenship behavior directed at the organization

${ }^{\dagger} p \leq 0.10 .{ }^{*} p \leq 0.05 .{ }^{* *} p \leq 0.01$
Funding This work was supported by a dissertation research support grant awarded to the first author for their dissertation.

\section{References}

Abrams, D., \& Hogg, M. A. (1988). Comments on the motivational status of self-esteem in social identity and intergroup discrimination. European JouRnal of Social Psychology, 18, 317-334. https://doi.org/10.1002/ejsp.2420180403

Aguinis, H., Villamor, I., \& Ramani, R. M. (2020). MTurk research: Review and recommendations. Journal of Management, 47, 823-837. https://doi.org/10.1177/0149206320969787

Arndt, J., Lieberman, J. D., Cook, A., \& Solomon, S. (2005). Terror management in the courtroom: Exploring the effects of mortality salience on legal decision making. Psychology, Public Policy, and Law, 11, 407-438. https://doi.org/10.1037/1076-8971.11.3. 407

Arndt, J., \& Solomon, S. (2003). The control of death and the death of control: The effects of mortality salience, neuroticism, and worldview threat on the desire for control. Journal of Research in Personality, 37, 1-22. https://doi.org/10.1016/S0092-6566(02) 00530-5

Arndt, J., Solomon, S., Kasser, T., \& Sheldon, K. M. (2004). The urge to splurge: A terror management account of materialism and consumer behavior. Journal of Consumer Psychology, 14, 198-212. https://doi.org/10.1207/s15327663jcp1403_2
Ashforth, B. E., \& Mael, F. (1989). Social identity theory and the organization. Academy of Management Review, 14, 20-39. https://doi.org/10.5465/amr.1989.4278999

Bagozzi, R. P., \& Edwards, J. R. (1998). A general approach for representing constructs in organizational research. Organizational Research Methods, 1, 45-87. https://doi.org/10.1177/10944 2819800100104

Baron, R. M., \& Kenny, D. A. (1986). The moderator-mediator variable distinction in social psychological research: Conceptual, strategic, and statistical considerations. Journal of Personality and Social Psychology, 51, 1173-1182. https://doi.org/10.1037/ 0022-3514.51.6.1173

Batson, C. D. (1987). Prosocial motivation: Is it ever truly altruistic? In L. Berkowitz (Ed.), Advances in experimental social psychology (pp. 65-122). San Diego, CA: Academic Press. https://doi.org/ 10.1016/S0065-2601(08)60412-8

Becker, T. E., Atinc, G., Breaugh, J. A., Carlson, K. D., Edwards, J. R., \& Spector, P. E. (2016). Statistical control in correlational studies: 10 essential recommendations for organizational researchers. Journal of Organizational Behavior, 37, 157-167. https://doi. org/10.1002/job.2053

Belmi, P., \& Pfeffer, J. (2016). Power and death: Mortality salience increases power seeking while feeling powerful reduces death anxiety. Journal of Applied Psychology, 101, 702-720. https:// doi.org/10.1037/apl0000076

Bentler, P. M., \& Chou, C. P. (1987). Practical issues in structural modeling. Sociological Methods \& Research, 16, 78-117. https:// doi.org/10.1177/0049124187016001004

Breaugh, J. A. (2008). Important considerations in using statistical procedures to control for nuisance variables in nonexperimental 
studies. Human Resource Management Review, 18, 282-293. https://doi.org/10.1016/j.hrmr.2008.03.001

Byron, K., \& Peterson, S. (2002). The impact of a large-scale traumatic event on individual and organizational outcomes: Exploring employee and company reactions to September 11, 2001. Journal of Organizational Behavior, 23, 895-910. https://doi. org/10.1002/job.176

Carlson, K. D., \& Wu, J. (2012). The illusion of statistical control: Control variable practice in management research. Organizational Research Methods, 15, 413-435. https://doi.org/10.1177/10944 28111428817

Carstensen, L. L., Isaacowitz, D. M., \& Charles, S. T. (1999). Taking time seriously: A theory of socioemotional selectivity. American Psychologist, 54, 165-181. https://doi.org/10.1037/0003-066X. 54.3.165

Chatard, A., Hirschberger, G., \& Pyszczynski, T. (2020). A word of caution about Many Labs 4: If you fail to follow your preregistered plan, you may fail to find a real effect. https://doi.org/10. 31234/osf.io/ejubn

Cheung, J. H., Burns, D. K., Sinclair, R. R., \& Sliter, M. (2017). Amazon Mechanical Turk in organizational psychology: An evaluation and practical recommendations. Journal of Business and Psychology, 32, 347-361. https://doi.org/10.1007/ s10869-016-9458-5

Cook, T. D., Campbell, D. T., \& Peracchio, L. (1990). Quasi experimentation. In M. D. Dunnette \& L. M. Hough (Eds.), Handbook of industrial and organizational psychology (pp. 491-576). Consulting Psychologists Press.

Cox, C. R., Darrell, A., \& Arrowood, R. B. (2019). The method behind the science: A guide to conducting terror management theory research. In C. Routledge, \& M. Vess (Eds.). Handbook of terror management theory (pp. 85-132). San Diego, CA: Elsevier Academic Press. https://doi.org/10.1016/B978-0-12-811844-3. 00004-4

Cozzolino, P. J. (2006). Death contemplation, growth, and defense: Converging evidence of dual existential systems? Psychological Inquiry, 17, 278-287. https://doi.org/10.1080/1047840070 1366944

Cozzolino, P. J., Staples, A. D., Meyers, L. S., \& Samboceti, J. (2004). Greed, death, and values: From terror management to transcendence management theory. Personality and Social Psychology Bulletin, 30, 278-292. https://doi.org/10.1177/0146167203 260716

DeSimone, J. A., Harms, P. D., \& DeSimone, A. J. (2015). Best practice recommendations for data screening. Journal of Organizational Behavior, 36, 171-181. https://doi.org/10.1002/job.1962

Edwards, J. R., \& Lambert, L. S. (2007). Methods for integrating moderation and mediation: A general analytical framework using moderated path analysis. Psychological Methods, 12, 1-22. https://doi.org/10.1037/1082-989X.12.1.1

Ehrhart, M. G., \& Naumann, S. E. (2004). Organizational citizenship behavior in work groups: A group norms approach. Journal of Applied Psychology, 89, 960-974. https://doi.org/10.1037/00219010.89.6.960

Erikson, E. H., \& Erikson, J. M. (1998). The life cycle completed (extended version). New York, NY: W. W. Norton \& Company.

Frias, A., Watkins, P. C., Webber, A. C., \& Froh, J. J. (2011). Death and gratitude: Death reflection enhances gratitude. Journal of Positive Psychology, 6, 154-162. https://doi.org/10.1080/17439 760.2011 .558848

Goldenberg, J. L., Hart, J., Pyszczynski, T., Warnica, G. M., Landau, M., \& Thomas, L. (2006). Ambivalence toward the body: Death, neuroticism, and the flight from physical sensation. Personality and Social Psychology Bulletin, 32, 1264-1277. https://doi.org/ 10.1177/0146167206289505
Goodman, J. K., Cryder, C. E., \& Cheema, A. (2013). Data collection in a flat world: The strengths and weaknesses of Mechanical Turk samples. Journal of Behavioral Decision Making, 26, 213-224. https://doi.org/10.1002/bdm.1753

Grant, A. M. (2007). Relational job design and the motivation to make a prosocial difference. Academy of Management Review, 32, 393-417. https://doi.org/10.5465/amr.2007.24351328

Grant, A. M. (2008). Does intrinsic motivation fuel the prosocial fire? Motivational synergy in predicting persistence, performance, and productivity. Journal of Applied Psychology, 93, 48-58. https:// doi.org/10.1037/0021-9010.93.1.48

Grant, A. M., \& Mayer, D. M. (2009). Good soldiers and good actors: Prosocial and impression management motives as interactive predictors of affiliative citizenship behaviors. Journal of Applied Psychology, 94, 900-912. https://doi.org/10.1037/a0013770

Grant, A. M., \& Sumanth, J. J. (2009). Mission possible? The performance of prosocially motivated employees depends on manager trustworthiness. Journal of Applied Psychology, 94, 927-944. https://doi.org/10.1037/a0014391

Grant, A. M., \& Wade-Benzoni, K. (2009). The hot and cool of death awareness at work: Mortality cues, aging, and self-protective and prosocial motivations. Academy of Management Review, 34, 600-622. https://doi.org/10.5465/amr.34.4.zok600

Greenberg, J., Koole, S., \& Pyszczynski, T. (2004). Handbook of experimental existential psychology. Guilford Press.

Greenberg, J., Pyszczynski, T., \& Solomon, S. (1986). The causes and consequences of the need for self-esteem: A terror management theory. In R. F. Baumeister (Ed.), Public self and private self (pp. 189-212). Springer-Verlag.

Greenberg, J., Simon, L., Pyszczynski, T., Solomon, S., \& Chatel, D. (1992). Terror management and tolerance: Does mortality salience always intensify negative reactions to others who threaten one's worldview? Journal of Personality and Social Psychology, 63, 212-222. https://doi.org/10.1037/0022-3514.63.2.212

Hart, J. (2014). Toward an integrative theory of psychological defense. Perspectives on Psychological Science, 9, 19-39. https://doi.org/ 10.1177/1745691613506018

Haslam, S. A. (2004). Psychology in organizations: The social identity approach. Sage.

Hinkin, T. R. (1995). A review of scale development practices in the study of organizations. Journal of Management, 21, 967-988. https://doi.org/10.1177/014920639502100509

Hogg, M. A., Terry, D. J., \& White, K. M. (1995). A tale of two theories: A critical comparison of identity theory with social identity theory. Social Psychology Quarterly, 58, 255-269. https://doi. org/10.2307/2787127

Holland, S. J., Shore, D. B., \& Cortina, J. M. (2016). Review and recommendations for integrating mediation and moderation. Organizational Research Methods, 20, 686-720. https://doi.org/ 10.1177/1094428116658958

Infurna, F. J., \& Jayawickreme, E. (2019). Fixing the growth illusion. New directions for research in resilience and posttraumatic growth. Current Directions in Psychological Science, 28, 152158. https://doi.org/10.1177/0963721419827017

Jacobsen, A., \& Beehr, T. A. (2018). When death is a good thing: A model examining mortality cues, death awareness, and safety behavior. Academy of Management Annual Meeting Proceedings, 2018. https://doi.org/10.5465/AMBPP.2018.14413abstract

Jacobsen, A., \& Beehr, T. A. (2020a, August). Mortality cue threats, death anxiety, and employee well-being: A moderated mediation model. In P. Bamberger (Chair), Death and work: Utilizing diverse methods to integrate mortality into management research. Symposium conducted at the annual conference of the Academy of Management, Vancouver, BC.

Jacobsen, A., \& Beehr, T. A. (2020b). Mortality salience in the workplace: An integrative review and implications for supervising 
jobs with high exposure to death. In A. M. Rossi, J. A. Meurs, \& P. L. Perrewe (Eds.), Stress and quality of working life: Finding meaning in grief and suffering (pp. 61-80). Information Age Publishing.

Janoff-Bulman, R. (1992). Shattered assumptions. Free Press.

Jolly, J. B., Dyck, M. J., Kramer, T. A., \& Wherry, J. N. (1994). Integration of positive and negative affectivity and cognitive content-specificity: Improved discrimination of anxious and depressive symptoms. Journal of Abnormal Psychology, 103, 544-552. https://doi.org/10.1037/0021-843x.103.3.544

Jonas, E., Schimel, J., Greenberg, J., \& Pyszczynski, T. (2002). The scrooge effect: Evidence that mortality salience increases prosocial attitudes and behavior. Personality and Social Psychology Bulletin, 28, 1342-1353. https://doi.org/10.1177/ 014616702236834

Jöreskog, K. G., \& Sörbom, D. (1993). LISREL 8, Structural equation modeling with the SIMPLIS command language. Scientific Software International.

Juhl, J., \& Routledge, C. (2016). Putting the terror in terror management theory: Evidence that the awareness of death does cause anxiety and undermine psychological well-being. Current Directions in Psychological Science, 25, 99-103. https:// doi.org/10.1177/0963721415625218

Kasser, T. (2002). Sketches for a self-determination theory of values. In E. L. Deci \& R. M. Ryan (Eds.), Handbook of self-determination research (pp. 123-140). University of Rochester Press.

Kastenbaum, R. (2000). The psychology of death. Springer Publishing Company.

Kees, J., Berry, C., Burton, S., \& Sheehan, K. (2017). An analysis of data quality: Professional panels, student subject pools, and Amazon's Mechanical Turk. Journal of Advertising, 46, 141-155. https://doi.org/10.1080/00913367.2016.1269304

Keith, M. G., Tay, L., \& Harms, P. D. (2017). Systems perspective of Amazon Mechanical Turk for organizational research: Review and recommendations. Frontiers in Psychology, 8, 1-19. https://doi.org/10.3389/fpsyg.2017.01359

Klein, R. A., Cook, C. L., Ebersole, C. R., Vitiello, C. A., Nosek, B. A., Chartier, C. R., ... Ratliff, K. A. (2019). Many Labs 4: Failure to replicate mortality salience effect with and without original author involvement. https://doi.org/10.31234/osf.io/vef2c

Lambert, A. J., Eadeh, F. R., Peak, S. A., Scherer, L. D., Schott, J. P., \& Slochower, J. M. (2014). Toward a greater understanding of the emotional dynamics of the mortality salience manipulation: Revisiting the "affect-free" claim of terror management research. Journal of Personality and Social Psychology, 106, 655-678. https://doi.org/10.1037/a0036353

Lee, K., \& Allen, N. J. (2002). Organizational citizenship behavior and workplace deviance: The role of affect and cognitions. Journal of Applied Psychology, 87, 131-142. https://doi.org/10.1037/ 0021-9010.87.1.131

Little, T. D., Cunningham, W. A., Shahar, G., \& Widaman, K. F. (2002). To parcel or not to parcel: Exploring the question, weighing the merits. Structural Equation Modeling, 9, 151-173. https://doi.org/10.1207/S15328007SEM0902_1

Liu, W., Zhou, Z. E., \& Che, X. X. (2019). Effect of workplace incivility on OCB through burnout: The moderating role of affective commitment. Journal of Business and Psychology, 34, 657-669. https://doi.org/10.1007/s10869-018-9591-4

Lykins, E. L., Segerstrom, S. C., Averill, A. J., Evans, D. R., \& Kemeny, M. E. (2007). Goal Shifts Following Reminders of Mortality: Reconciling Posttraumatic Growth and Terror Management Theory. Personality and Social Psychology Bulletin, 33(8), 1088-1099. https://doi.org/10.1177/0146167207303015

MacKenzie, S. B., Podsakoff, P. M., \& Fetter, R. (1993). The impact of organizational citizenship behavior on evaluations of salesperson performance. Journal of Marketing, 57, 70-80. https://doi.org/ $10.2307 / 1252058$

MacKinnon, D. P., Coxe, S., \& Baraldi, A. N. (2012). Guidelines for the investigation of mediating variables in business research. Journal of Business and Psychology, 27, 1-14. https://doi.org/ 10.1007/s10869-011-9248-Z

Mael, F., \& Ashforth, B. E. (1992). Alumni and their alma mater: A partial test of the reformulated model of organizational identification. Journal of Organizational Behavior, 13, 103-123. https://doi.org/10.1002/job.4030130202

Maxfield, M., Pyszczynski, T., Kluck, B., Cox, C. R., Greenberg, J., Solomon, S., \& Wise, D. (2007). Age related differences to thought of one's own death: Mortality salience judgments of moral transgressions. Psychology and Aging, 2, 341-353. https://doi.org/10.1037/0882-7974.22.2.341

McAdams, D. P., \& de St. Aubin, E. . (1992). A theory of generativity and its assessment through self-report, behavioral acts, and narrative themes in autobiography. Journal of Personality and Social Psychology, 62, 1003-1015. https://doi.org/10.1037/ 0022-3514.62.6.1003

McGregor, H. A., Lieberman, J. D., Greenberg, J., Solomon, S., Arndt, J., Simon, L., \& Pyszczynski, T. (1998). Terror management and aggression: Evidence that mortality salience motivates aggression against worldview-threatening others. Journal of Personality and Social Psychology, 74, 590-605. https://doi. org/10.1037/0022-3514.74.3.590

Meglino, B. M., \& Korsgaard, A. (2004). Considering rational selfinterest as a disposition: Organizational implications of other orientation. Journal of Applied Psychology, 89, 946-959. https://doi.org/10.1037/0021-9010.89.6.946

Metcalfe, J., \& Mischel, W. (1999). The hot/cool-system analysis of delay of gratification: Dynamics of willpower. Psychological Review, 106, 3-19. https://doi.org/10.1037/0033-295X.106.1.3

Murphy, K. R., \& Russell, C. J. (2016). Mend it or end it: Redirecting the search for interactions in the organizational sciences. Organizational Research Methods, 20, 549-573. https://doi. org/10.1177/1094428115625322

Naseer, S., Bouckenooghe, D., Syed, F., Khan, A. K., \& Qazi, S. (2020). The malevolent side of organizational identification: Unraveling the impact of psychological entitlement and manipulative personality on unethical work behaviors. Journal of Business and Psychology, 35, 333-346. https://doi.org/10. 1007/s10869-019-09623-0

Nasser, F., \& Takahashi, T. (2003). The effect of using item parcels on ad hoc goodness-of-fit indexes in confirmatory factor analysis: An example using Sarason's reactions to tests. Applied Measurement in Education, 16, 75-97. https://doi.org/10.1207/ S15324818AME1601_4

Neimeyer, R. A., \& Moore, M. K. (1994). Validity and reliability of the multidimensional fear of death scale. In R. A. Neimeyer (Ed.), Death anxiety handbook: Research, instrumentation, and application (pp. 103-119). Taylor \& Francis.

Nunnally, J. C. (1967). Psychometric theory. McGraw-Hill.

Nyatanga, B., \& de Vocht, H. (2006). Towards a definition of death anxiety. Journal of Palliative Nursing, 12, 410-413. https:// doi.org/10.12968/ijpn.2006.12.9.21868

Organ, D. W. (1988). Organizational citizenship behavior: The good soldier syndrome. Lexington, MA: Lexington Books.

Organ, D. W. (1997). Organizational citizenship behavior: It's construct clean-up time. Human Performance, 10, 85-97. https:// doi.org/10.1207/s15327043hup1002_2

Organ, D. W., Podsakoff, P. M., \& MacKenzie, S. B. (2006). Organizational citizenship behavior: Its nature, antecedents, and consequences. Thousand Oaks, CA: Sage.

Peer, E., Vosgerau, J., \& Acquisti, A. (2014). Reputation as a sufficient condition for data quality on Amazon Mechanical Turk. 
Behavior Research Methods, 46, 1023-1031. https://doi.org/ 10.3758/s13428-013-0434-y

Peterson, B. E., \& Stewart, A. J. (1996). Antecedents and contexts of generativity motivation at midlife. Psychology and Aging, 11, 21-33. https://doi.org/10.1037/0882-7974.11.1.21

Podsakoff, P. M., MacKenzie, S. B., Paine, J. B., \& Bachrach, D. G. (2000). Organizational citizenship behaviors: A critical review of the theoretical and empirical literature and suggestions for future research. Journal of Management, 26, 513-563. https://doi.org/ 10.1177/014920630002600307

Podsakoff, P. M., MacKenzie, S. B., \& Podsakoff, N. P. (2012). Sources of method bias in social science research and recommendations on how to control it. Annual Review of Psychology, 63, 539-569. https://doi.org/10.1146/annurev-psych-120710-100452

Pollak, J. M. (1980). Correlates of death anxiety: A review of empirical studies. Omega: Journal of Death and Dying, 10, 97-121. https:// doi.org/10.2190/4KG5-HBH0-NNME-DM58

Pyszczynski, T., Solomon, S., \& Greenberg, J. (2003). In the wake of 9/11, Rising above the terror. the wake of 9/11, The psychology of terror (pp. 189-198). American Psychological Association.

Ring, K., \& Elsaesser Valarino, E. (1998). Lessons from the light: What we can learn from the near-death experience. Perseus.

Rioux, S. M., \& Penner, L. A. (2001). The causes of organizational citizenship behavior: A motivational analysis. Journal of Applied Psychology, 86, 1306-1314. https://doi.org/10.1037/0021-9010. 86.6.1306

Roberts, J. R., \& Maxfield, M. (2019). Mortality salience and age effects on charitable donations. American Behavioral Scientist, 63, 1863-1884. https://doi.org/10.1177/0002764219850864

Rogelberg, S. G., \& Stanton, J. M. (2007). Introduction: Understanding and dealing with organizational survey nonresponse. Organizational Research Methods, 10, 195-209. https://doi.org/10.1177/ 1094428106294693

Routledge, C., \& Arndt, J. (2008). Self-sacrifice as self-defence: Mortality salience increases efforts to affirm a symbolic immortal self at the expense of the physical self. European Journal of Social Psychology, 38, 531-541. https://doi.org/10.1002/ejsp.442

Siemsen, E., Roth, A., \& Oliveira, P. (2010). Common method bias in regression models with linear, quadratic, and interaction effects. Organizational Research Methods, 13, 456-476. https://doi.org/ 10.1177/1094428109351241

Sliter, M. T., Sinclair, R. R., Yuan, Z., \& Mohr, C. D. (2014). Don't fear the reaper: Trait death anxiety, mortality salience, and occupational health. Journal of Applied Psychology, 99, 759-769. https://doi.org/10.1037/a0035729

Stein, J. H., \& Cropanzano, R. (2011). Death awareness and organizational behavior. Journal of Organizational Behavior, 32, 11891193. https://doi.org/10.1002/job.715

Tedeschi, R. G., \& Calhoun, L. G. (1996). The posttraumatic growth inventory: Measuring the positive legacy of trauma. Journal of
Traumatic Stress, 9, 455-472. https://doi.org/10.1002/jts.24900 90305

Tedeschi, R. G., \& Calhoun, L. G. (2004). Posttraumatic growth: Conceptual foundations and empirical evidence. Psychological Inquiry, 15, 1-18. https://doi.org/10.1207/s15327965pli1501_01

Thorson, J. A., \& Powell, F. C. (1992). A revised death anxiety scale. Death Studies, 16, 507-521. https://doi.org/10.1080/0748118920 8252595

van Knippenberg, D., \& van Schie, E. C. M. (2000). Foci and correlates of organizational identification. Journal of Occupational and Organizational Psychology, 73, 137-147. https://doi.org/10. 1348/096317900166949

Van Scotter, J., Motowidlo, S. J., \& Cross, T. C. (2000). Effects of task performance and contextual performance on systemic rewards. Journal of Applied Psychology, 85, 526-535. https://doi.org/10. 1037/0021-9010.85.4.526

Vroom, V. H. (1964). Work and motivation. Wiley.

Walter, S., Seibert, S., Goering, D., \& O'Boyle, E. (2018). A tale of two sample sources: Do results from online panel data and conventional data converge? Journal of Business and Psychology, 34, 1-28. https://doi.org/10.1007/s10869-018-9552-y.

Watson, D., Clark, L. A., \& Tellegen, A. (1988). Development and validation of brief measures of positive and negative affect: The PANAS scales. Journal of Personality and Social Psychology, 54, 1063-1070. https://doi.org/10.1037//0022-3514.54.6.1063

Williams, L. J., \& Anderson, S. E. (1991). Job satisfaction and organizational commitment as predictors of organizational citizenship and in-role behaviors. Journal of Management, 17, 601-617. https://doi.org/10.1177/014920639101700305

Wrzesniewski, A. (2002). "It's not just a job": Shifting meanings of work in the wake of 9/11. Journal of Management Inquiry, 11, 230-234. https://doi.org/10.1177/1056492602113003

Wu, C., Liu, J., Kwan, H. K., \& Lee, C. (2016). Why and when workplace ostracism inhibits organizational citizenship behaviors: An organizational identification perspective. Journal of Applied Psychology, 101, 362-378. https://doi.org/10.1037/apl0000063

Xu, H., \& Brucks, M. L. (2011). Are Neurotics Really More Creative? Neuroticism's Interaction With Mortality Salience in Determining Creative Interest. Basic and Applied Social Psychology, 33(1), 88-99. https://doi.org/10.1080/01973533.2010.539962

Yalom, I. D. (2008). Staring at the sun: Overcoming the terror of death. Jossey-Bass.

Zhang, Y., Liu, X., \& Chen, W. (2020). Fight and flight: A contingency model of third parties' approach-avoidance reactions to peer abusive supervision. Journal of Business and Psychology, 767-782. https://doi.org/10.1007/s10869-019-09650-x.

Publisher's Note Springer Nature remains neutral with regard to jurisdictional claims in published maps and institutional affiliations. 